\title{
ACRYLAMIDE IN FOOD : AN OVERVIEW
}

\author{
Youssef, M. M.*, H. A. Abou-Gharbia \& H. A. Abou-Bakr \\ Food Science \& Technology Dept., \\ Fac. of Agric., El-Shatby, 21545 \\ Univ. of Alexandria, Alexandria, Egypt.
}

\begin{abstract}
The risk of acrylamide has only come to the attention of scientists recently, as its discovery in foods was accidental. Acrylamide is formed in many types of food cooked at high temperatures, presence of acrylamide in many foods has been recently reported. Four main theories have been proposed to explain the mechanisms by which acrylamide is formed in food: Theory 1 : Direct formation from amino acids; Theory $2:$ Pathways based on acrolein intermediates; Theory 3 : Pathways based on an acrylic acid intermediate and Theory 4 : Pathways based on Maillard browning precursors .A hypothesis that acrylamide is formed by/upon cooking was confirmed in experimental animals by verification of the identity of the acrylamide adduct in haemoglobin $(\mathrm{Hb})$. This was comprehensively approved by GC/MS analysis and the demonstration that the increased adduct levels were compatible with expectation from the contents of acrylamide determined in fried feeds. A significant dependence of acrylamide formation on temperature was demonstrated. Extensive efforts have been made to assess human exposure to acrylamide by monitoring several metabolites excreted in the urine as well as products resulting from biological alkylation by acrylamide. Results from in vivo studies conducted on rats explored that dermal absorption ranged from approximately 14 to $61 \%$ of the applied dose. Meanwhile, it was obvious that acrylamide is widely distributed in all tissues of the body. The major metabolite formed from acrylamide via the cytochrome P450 pathway is glycidamide. Conjugation to reduced glutathione (GSH) catalyzed by glutathione S-transferase (GST) and excretion as mercapturic acid is a major pathway for the metabolism of acrylamide. Experiments revealed neuro and reproductive toxicity of acrylamide. Notwithstanding, the International Agency of Research on Cancer (IARC) has classified acrylamide as "probably carcinogenic to humans". Acrylamide in foods can be determined by GC/MS, HPLC and liquid chromatography-mass spectrometry (LC-MS) using the MS/MS mode. For the GC/MS and HPLC methods, the achieved detection level of acrylamide was $5 \mu \mathrm{g} / \mathrm{kg}$ while for LC-MS/MS method was $10 \mu \mathrm{g} / \mathrm{kg}$. The latter method is simple and preferable for routine analysis.
\end{abstract}

Key Words : amino acids, acrylamide, Maillard reaction, heating, distribution, absorption, metabolism, toxicity, carcinogencity, determination, food, acrolein, acrylic acid.

\section{INTRODUCTION}

Acrylamide is a chemical substance whose major use is to produce polyacrylamide, a coagulant used in drinking water and waste water treatment. Acrylamide is also used in the construction of foundations for tunnels and sewers. The risk of acrylamide has only recently come to the attention of scientists and its discovery was accidental. In one of acrylamide applications, the construction of the Hallandsas railway tunnel in Southern Sweden, acrylamide was used to repair water leaks that had developed in the tunnel. It is worth to mention that not all of the acrylamide hardened into the polymer and some of the acrylamide seeped into an adjacent river with the result that fish were killed and several cows that drank from the river were paralyzed. Concern about the health of the tunnel workers (acrylamide was a known carcinogen in rats and a neurotoxin in occupationally-exposed workers) led a group of scientists to develop a test that measured the presence of an- acrylamide-protein adduct in blood. The investigators not only found this adduct in the exposed tunnel workers, but also among members of the general population that had no known occupational exposure to acrylamide (Rosen, 2002).

In April 2002, the Swedish scientists and Swedish National Food Administration (NFA) called a press conference to announce that they had found "alarmingly" high quantities of acrylamide in bread, biscuits, cereal, potato chips and French fries. Lief Busk, head of Sweden's NFA said "I have been in this field thirty years and I have never seen anything like this before" (Rosen, 2002).

In June 2002 and because of the possible importance of the aforementioned findings to human health, WHO \& FAO convened a meeting of 23 scientific experts from all over the world to assess the situation. After 3 days of consultations, the experts agreed that they did not yet have enough information to assess how much risk if any, acrylamide posed and

* The author to whom correspondences could be addressed. 
they identified a number of important issues for which more research was needed (Rosen, 2002). Accordingly, investigators have looked for other sources of acrylamide.

European researchers have recently reported presence of acrylamide in many foods (Hofler et al., 2002 \& Tareke et al., 2002). After these papers, many institutions have begun to analyze acrylamide in food products. For example, the U.S. Food and Drug Administration (FDA) reported the analysis of acrylamide in 286 commercial food products. Their results ranged from none detected to $1184 \mathrm{ppb}$. Meanwhile, Swedish National Food Administration (NFA) in cooperation with University of Stockholm, Sweden, determined acrylamide in many Swedish Foods.
Notwithstanding, cigarette smoke was found to contain acrylamide.

It was obvious that acrylamide is formed in many types of food cooked at high temperatures (Table 1). Acrylamide was detected in high amounts in fried and baked starchbased foods. Such foods constitute the bulk of dietary intake and they are now wide spread globally. Consequently, concern for acrylamide has become priority issue for most countries (Naewbanij, 2002). At those times, nothing is known about the sources of acrylamide in foods. The data published so far indicate that a temperature $>100^{\circ} \mathrm{C}$ is required for its formation (Becalski et al., 2003).

Table 1 : Acrylamide levels in different foods and food product groups from Norway, Sweden, Switzerland, the United Kingdom and the United States of America.

\begin{tabular}{|c|c|c|c|c|}
\hline \multirow[b]{2}{*}{ Food/Product Group } & \multicolumn{4}{|c|}{ Acrylamide levels $(\mu \mathrm{g} / \mathrm{kg})^{1}$} \\
\hline & Mean $^{2}$ & Median $^{2}$ & $\begin{array}{l}\text { Minimum- } \\
\text { Maximum }\end{array}$ & $\begin{array}{c}\text { Number of } \\
\text { samples }\end{array}$ \\
\hline Crisps,potato/sweet potato ${ }^{3}$ & 1312 & 1343 & $170-2287$ & 38 \\
\hline Chips, potato ${ }^{4}$ & 537 & 330 & $<50-3500$ & 39 \\
\hline Batter based products & 36 & 36 & $<30-42$ & 2 \\
\hline Bakery products & 112 & $<50$ & $<50-450$ & 19 \\
\hline $\begin{array}{l}\text { Biscuits, crackers, toast, bread } \\
\text { crisps }\end{array}$ & 423 & 142 & $<30-3200$ & 58 \\
\hline Breakfast cereals & 298 & 150 & $<30-1346$ & 29 \\
\hline Crisps, corn & 218 & 167 & $34-416$ & 7 \\
\hline Bread, soft & 50 & 30 & $<30-162$ & 41 \\
\hline $\begin{array}{l}\text { Fish and seafood products, } \\
\text { crumbed, battered }\end{array}$ & 35 & 35 & $30-39$ & 4 \\
\hline Poultry or game, crumbed, battered & 52 & 52 & $39-64$ & 2 \\
\hline Instant malt drinks & 50 & 50 & $<50-70$ & 3 \\
\hline Chocolate powder & 75 & 75 & $<50-100$ & 2 \\
\hline Coffee powder & 200 & 200 & $170-230$ & 3 \\
\hline Beer & $<30$ & $<30$ & $<30$ & 1 \\
\hline
\end{tabular}

${ }^{1}$ The limits of detection and quantification varied among laboratories; values reported as less than a value are below the limit reported by the laboratory.

${ }^{2}$ Mean and median were calculated where individual data available; samples sizes were extremely small particularly for some food categories; where the mean and median are different it reflects the skewed distribution of the underlying data that were collected in different countries and may represent different food items within the larger category.

${ }^{3}$ Products that are thinly sliced and fried (Includes foods called potato chips in some regions including North America).

${ }^{4}$ Products that are more thickly sliced (Includes foods called French fries in some regions including North America).

The European Prospective Investigation into Cancer and Nutrition (EPIC), covers a large cohort of a half a million men and women from 23 European centers in 10 Western European countries (Denmark, France, Germany, Greece, Italy, Norway, Spain, Sweden, The Netherlands, and The United Kingdom). It is designed to study the relationship between diet and the risk of chronic disease, particularly cancer.

Ref : FAO/WHO, (2002). 


\section{1- What is acrylamide ?}

Acrylamide (2-propene amide or acrylic acid amide or vinyl amide) is an odourless, white crystalline solid at room temperature, with a molecular formula of $\mathrm{C}_{3} \mathrm{H}_{5} \mathrm{NO}$ and weight of 71.08 Dalton (Fig. 1). Acrylamide is readily soluble in water $\left(2155 \mathrm{~g} / 1\right.$ at $\left.30^{\circ} \mathrm{C}\right)$ and polar solvents (e.g. acetone, methanol and ethanol) but not in non-polar solvents (e.g. carbon tetrachloride). Acrylamide has a density of $1.27 \mathrm{~g} / 1\left(25^{\circ} \mathrm{C}\right)$, a boiling point of $136^{\circ} \mathrm{C}$ at $3.3 \mathrm{Kpa}$ and a melting point of 84$85^{\circ} \mathrm{C}$. Acrylamide contains an $\alpha, \beta-$ unsaturated amide system (Fig. 1) that reacts with nucleophilic compounds via a Michael addition. The major site of reaction is sulfhydryl groups present in proteins and amino acids (Anonymous, 2002a). It is worth to mention that acrylamide is a reactive molecules which undergoes free radical reactions and Michael addition reactions. The amide group does not activate the double bond as much as a carbonyl or acid group.

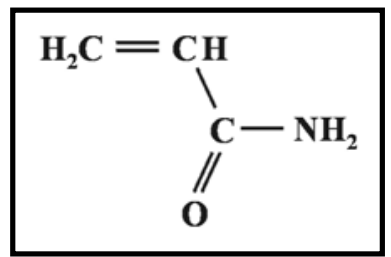

Fig. 1: Chemical structure of acrylamide

\section{2- Possible mechanisms for acrylamide} formation in foods :

A number of theories have been proposed to account for the mechanism by which acrylamide is formed in food. According to Rosen (2002), one possible route to acrylamide formation is the reaction of ammonia with either acrolein or its oxidation product, acrylic acid. Acrolein and acrylic acid are likely decomposed products of simple sugars undergoing non enzymatic browning. These materials may also be formed from the triacylglycerols liberated from the fats during frying or sautéing. Another possible mecha- nism envisions acrylic acid arising directly from the decomposition of two common amino acids, namely; alanine and aspartic acid. Still another common amino acid asparagine, could be directly converted to acrylamide by loss of two simple molecules, carbon dioxide and ammonia (a process whose driving force is predicted from the laws of thermodynamics). Asparagine and glutamine are found abundantly in wheat, corn and oats and contribute to non enzymatic browning of these grains by release of ammonia (Riha et al., 1996). Both of these amino acids are abundant in potatoes (Eppendorfer \& Bille, 1996).

Four theories have been proposed to explain the mechanism by which acrylamide is formed in foods :

\section{Theory 1 : Direct formation from amino ac-} ids :

The only certain fact in acrylamide formation is the necessity of a nitrogencontaining precursor. Since amino acids and proteins are the heads-on favorites-for this distinction, several acrylamide mechanisms based solely on amino acids have been proposed :

\section{(a) From alanine :}

According to Lindsay (2002), acrylamide can be formed from alanine through the following pathway shown in Fig. (2).

\section{(b) From asparagine and glutamine :}

Recent research has confirmed asparagine's role in acrylamide formation and strongly implicated glutamine in a low yield acrylamide pathway. Acrylamide can be formed from asparagine and glutamine through the following pathway proposed by Lindsay (2002) \& Friedman (2003).

Stable isotopes $\left({ }^{13} \mathrm{C}\right.$ and $\left.{ }^{15} \mathrm{~N}\right)$ were used to map reaction pathways. Sanders et al. (2002), reported three verification experiments as shown in Fig. (3).

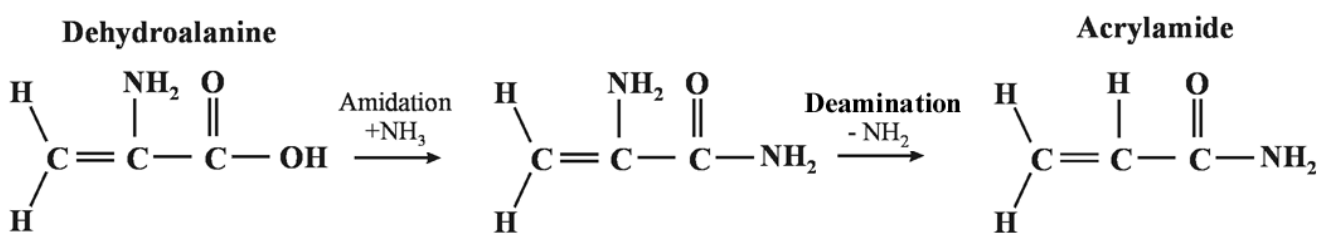

Fig. 2: Formation of acrylamide from aniline

Ref. : Lindsay (2002) 


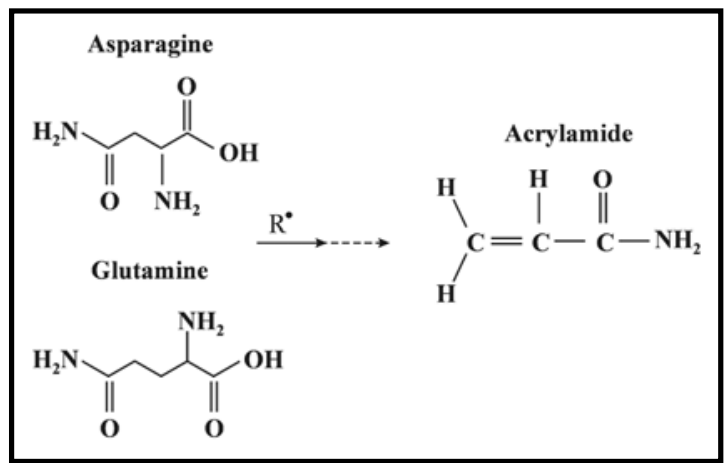

Step 1: Indicates the $\alpha$-carbon of asparagines is the focal point of reaction. It also indicates that an asparagines pathway exists exclusive of reducing sugar.

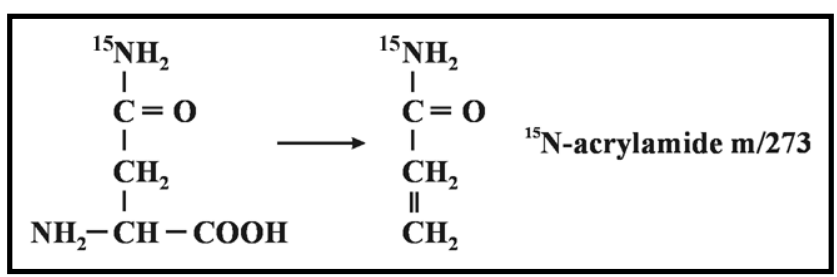

Step 2: Suggests that the $\alpha$-amino group does not participate in acrylamide formation.

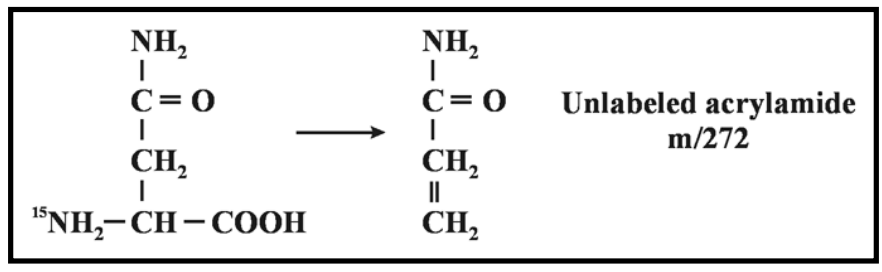

Step 3: Suggests that the amino acid $R$ group in asparagine remain intact instead of being assembled from pyrolytic fragments.

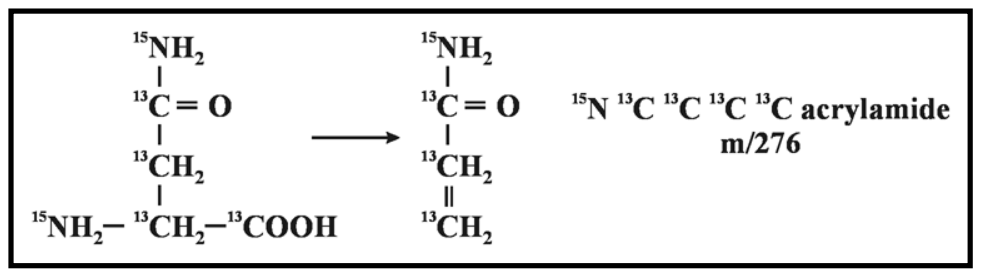

Fig. 3: Mapping the reaction pathway using stable isotopes $\left({ }^{13} \mathrm{C}\right.$ and $\left.{ }^{15} \mathrm{~N}\right)$

Ref. Sanders et al. (2003)

Glucose, fructose, sucrose, free asparagine and free glutamine were analyzed in 74 potato samples from 17 potato cultivars grown in 2002 at various locations in Switzerland and different farming systems. The potential of these potatoes for acrylamide formation was measured with a standardized heat treatment. These potentials correlated well with the product of the concentrations of reducing sugars and asparagine, glucose and fructose were found to determine acrylamide formation $\left(\mathrm{R}^{2}=0.9856\right)$. The cultivars showed large differences in their potential of acrylamide formation which was primarily related to their sugar contents. Agricultural practice neither influenced sugars and free asparagine nor the potential of acrylamide formation. Accordingly, acrylamide contents in potato products can be substantially reduced primarily by selecting cultivars with low concentrations of reducing sugars (Amrein et al., 2003).

A ribose asparagine combination was also found to produce acrylamide. The point of interest is that acrylamide in meat and other foods low in reducing sugars may arise from pyrolytic products of ribose in DNA and RNA. Meanwhile, numerous research papers 
have suggested involvement of dicarbonly compounds of their hydroxy carbonyl precursors in acrylamide formation from amino acids (Becalski et al., 2002, Lindsay, 2002; Mottram et al., 2002; Sanders et al., 2002).

\section{(c) From methionine :}

The following pathway (Fig. 4) was proposed by Lindsay (2002) to account for the mechanism by which acrylamide is formed in food.

\section{Theory 2 : Pathways based on acrolein in-} termediates :

Acrolein detection is common in samples testing positive for acrylamide (Stadler et al., 2002) and has certain structural similarities to acrylamide (Fig. 5). The ubiquity of acrylamide in compositionally diverse foods could be explained by the fact that acrolein can arise from degradation pathways of fats, carbohydrates and proteins.

Strecker degradation of methionine

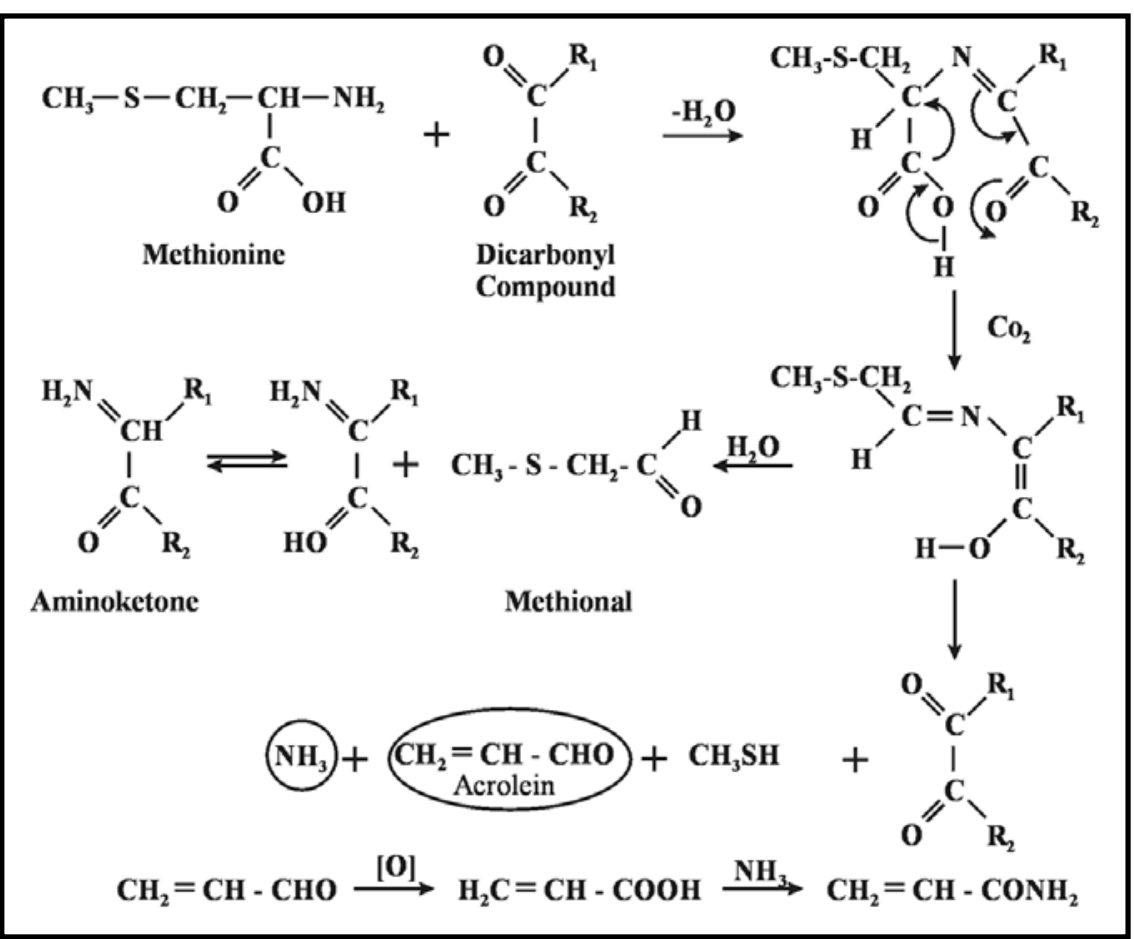

Fig. 4: Formation of acrylamide in food

Ref. Mottram \& Wedzicha (2002)

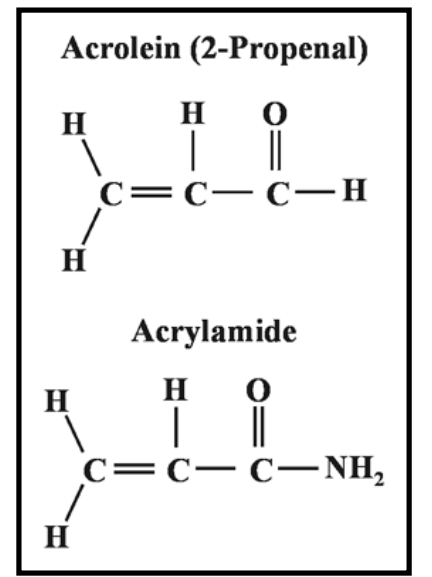

Fig. 5: Chemical structure of acrolein and acrylamide.

Ref. Stadler et al. ( 2002) 
Potential pathways of acrolein formation can be explained as follows:

\section{(a) Lipid pathways for acrolein :}

1. Glycerol dehydration : Hydrolysis of triacylglycerols gives free fatty acids and glycerol. The latter through dehydration gives a precursor for acrylamide (Lindsay, 2002).
Such a pathway can be explained as shown in fig. (6).

2. Oxidation of monoacylglycerol : Acrolein can be formed by oxidation of monoglycerol (Fig. 7). The following pathways were proposed for such a conversion by Lindsay (2002).

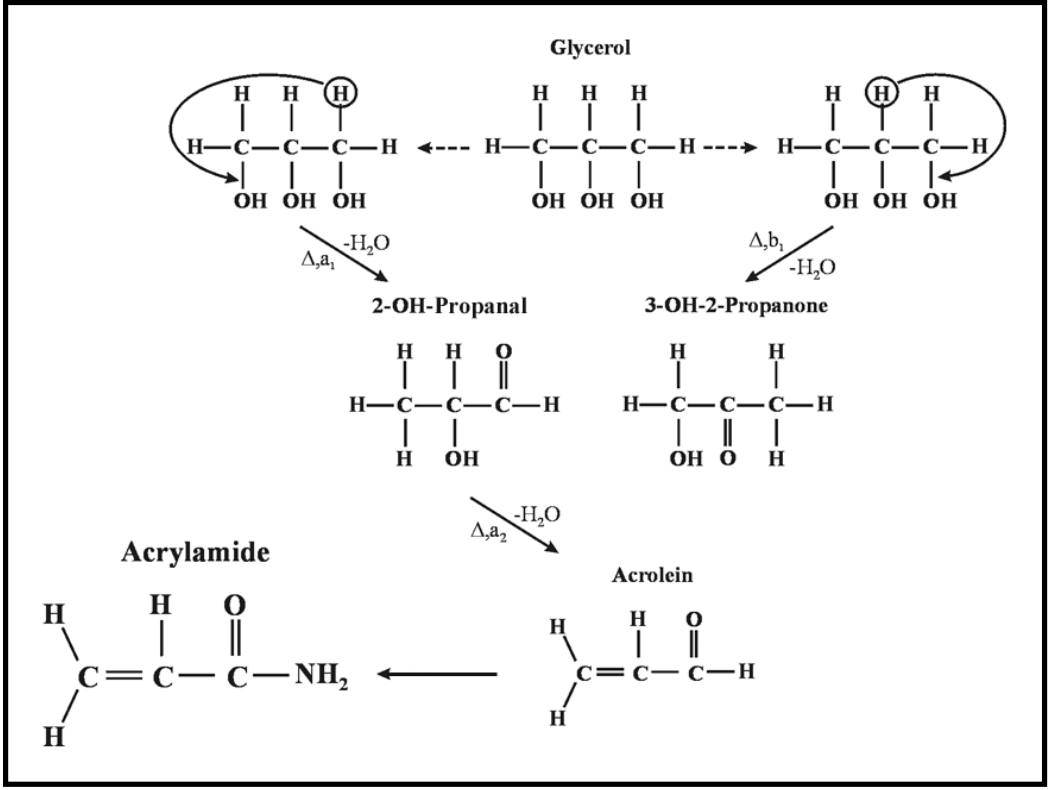

Fig. 6: Formation of acrolein through glucerol dehydration Ref. Lindsay (2002)

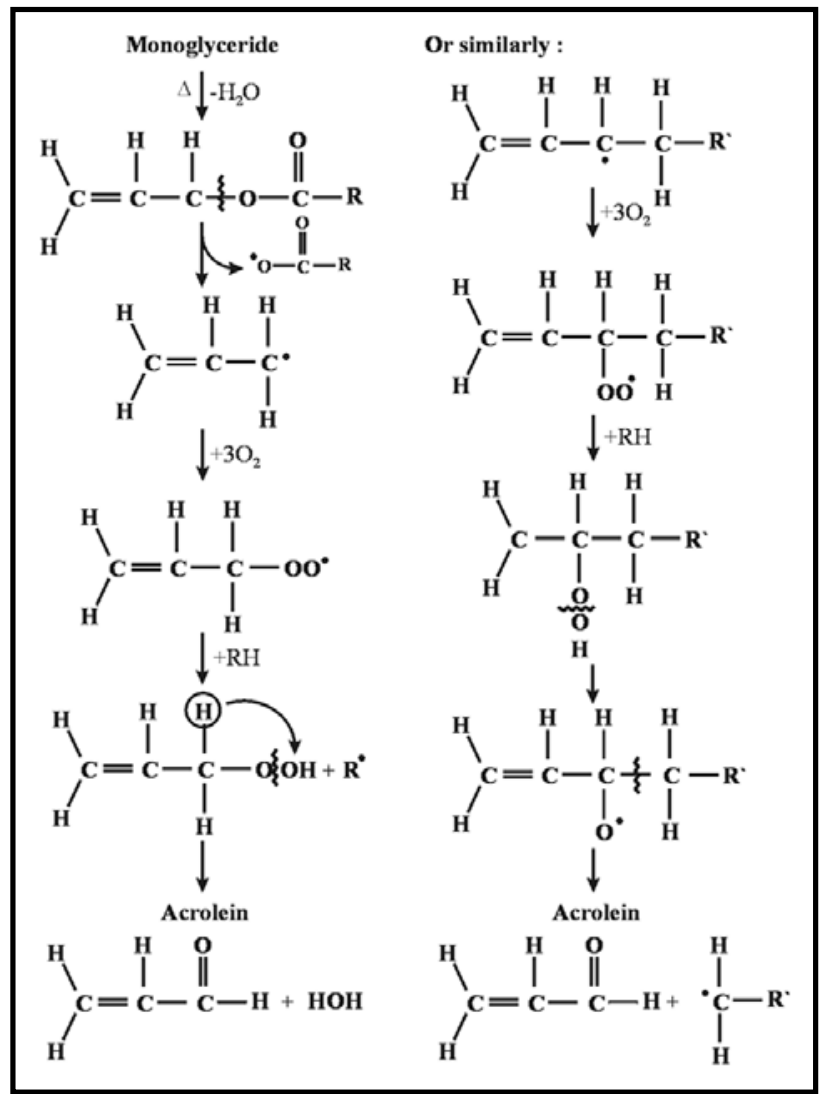

Fig. 7: Formation of acrolein by oxidation of monoglycerol Ref. Lindsay (2002) 
The point of interest is that potato samples fried in corn oil and paraffin oil (hydrocarbon-type oil devoid of triacylg-lycerols and thus of acrolein) exhibited very similar levels of acrylamide. Addition of ammonium carbonate, which decomposes to ammonia gas during frying, only negligibly altered levels of acrylamide when potatoes were fried in the aforementioned two oils. Thus, it appears that acrylamide is not principally formed from precursors (especially acrolein) present in the oil itself (Becalski et al., 2003).

\section{(b) Acrolein from starches and sugars:}

Acrolein pathways from sugars also exist. While these are not traditional Maillard type reactants, some evidence for this pathway appears to exist from research on tobacco pyrolysis. According to Lindsay (2002), acrolein can be formed from starches and sugars as shown in Fig. (8).

\section{(c) Acrolein from recombination of simple aldehydes :}

Pyrolysis, oxidation and irradiation of fats, proteins and carbohydrates give acetaldehyde and formaldehyde as ubiquitous byproducts. Acrolein production from acetaldehyde and formaldehyde have been proposed in the following pathway (Fig. 9, Lindsay, 2002).

$$
\begin{aligned}
& \text { Starch } \longrightarrow \text { Glucose } \longrightarrow \text { Fragments } \\
& \text { (1) } \\
& \text { (2) } \\
& \stackrel{\text { O }}{\mathbf{C}-\mathbf{H}} \\
& \text { l } \\
& \text { (3) } \\
& \Delta, 1) \text { and 2) } \\
& \begin{array}{l}
\text { 1) }-\mathrm{H}_{2} \mathrm{O} \\
\longrightarrow
\end{array} \quad \mathbf{C}=\stackrel{\mathrm{C}}{\mathrm{H}}-\stackrel{\mathrm{H}}{\mathbf{C}}-\mathbf{H} \\
& \text { (4) } \mathrm{H}-\mathrm{C}-\mathrm{OH} \\
& \mathrm{HO}-\mathrm{C}-\mathrm{H}
\end{aligned}
$$

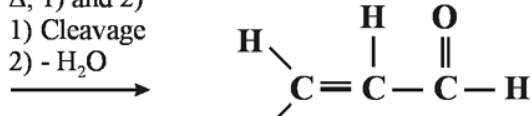

$$
\begin{aligned}
& \mathbf{H}^{\prime} \\
& \mathrm{CH}_{2} \mathrm{OH}
\end{aligned}
$$

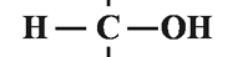

Fig. 8: Formation of acrolein starches and sugars

Ref. Lindsay (2002)

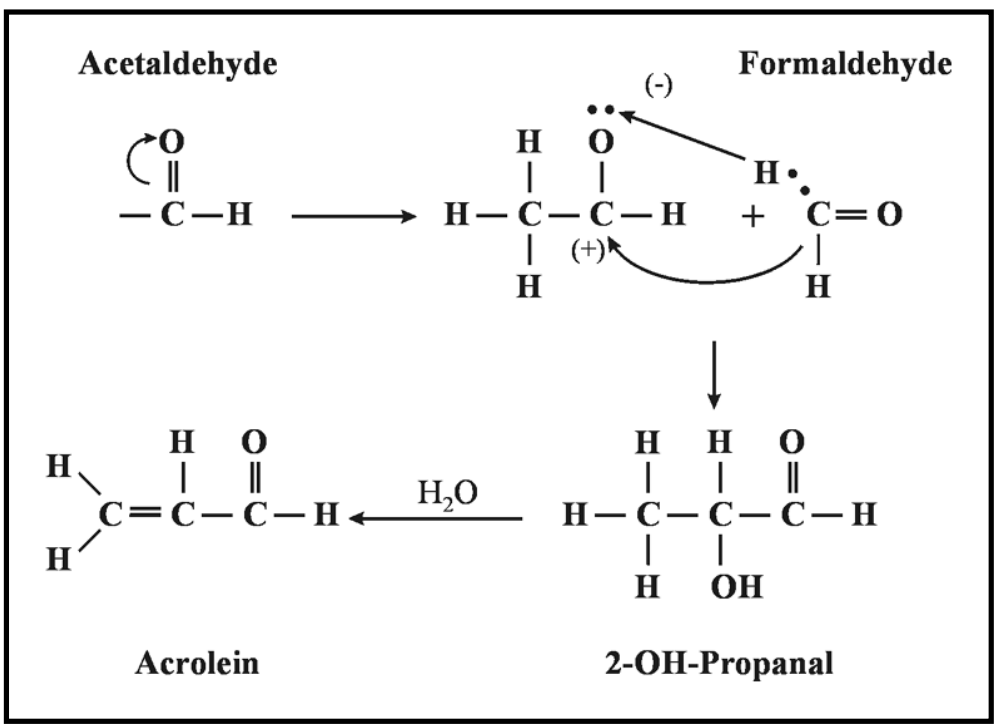

Fig. 9: Formation of acrolein from recombination of simple aldehydes

Ref. Lindsay (2002) 
Theory 3: Pathways based on an acrylic acid intermediate :

From the standpoint of organic chemistry, conversion of acrolein into an amide is difficult to envision. Acrylic acid/ammonia reaction offers much more compelling and a better documented pathway for amide synthesis (Friedman, 2003). Two mechanisms have been proposed by Lindsay (2002) for conversion of acrolein to acrylamide (Fig. 10). Such a conversion occurs either by direct oxidation of acrolein through an acrylic acid intermediate or by amination which may or may not have an acrylic acid intermediate.

Notwithstanding, acrylic acid formation has been proposed directly from alanine (Fig. 11).

Acrylamide production based on the reaction of ammonia with acrylic acid is straightforward and founded on an amination process well-documented in organic chemistry. Thermal desorption GC/MS confirms the presence of ammonia and acrylic acid in many acrylamide-containing foods (Stadler $e t$ $a l ., 2002)$. The significance of this mechanism is easy to test. Unless acrylic acid is limiting, increasing available ammonia would force higher acrylamide yields. However, ammonia addition in the from of heat labile ammonium carbonate does not significantly influence acrylamide production (Becalski et al., 2002). While $\mathrm{pH}$ and moisture could greatly influence this reaction in ways as yet not fully researched, it appears at present that the reaction between ammonia and acrylic acid plays at best a minor role in acrylamide formation.

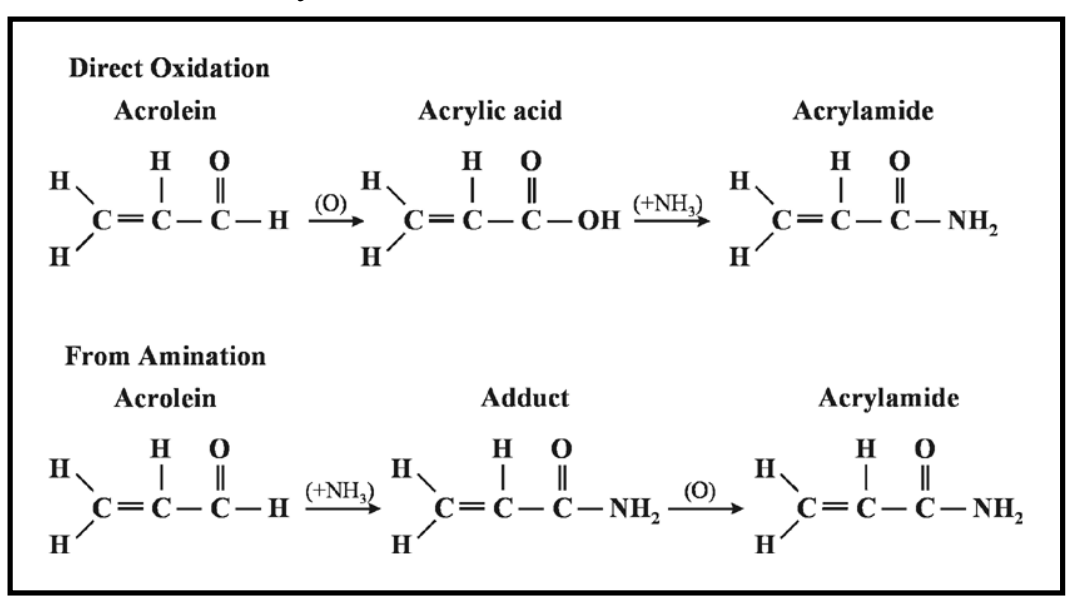

Fig. 10 : Conversion of acrolein to acryloamide Ref. Lindsay (2002)

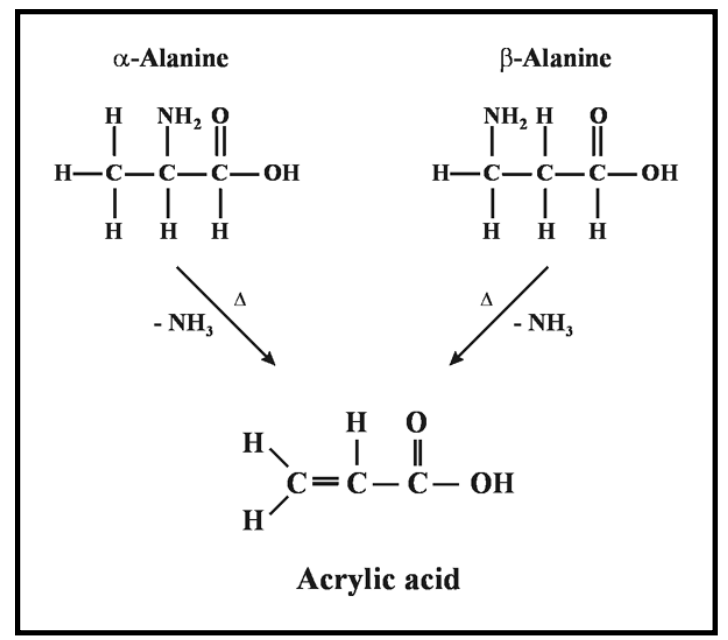

Fig. 11: Acrylic acid formation from alanine Ref. Lindsay (2002) 
Yasuhara et al., (2003) proposed formation mechanisms of acrylamide from an amino acid and a lipid through acrolein and acrylic acid (Fig. 12).

\section{Theory 4: Pathways based on Maillard Browning Precursors :}

Early analytical work observed acrylamide primarily in foods browned during preparation. There was a conjecture that Maillard browning precursors might be stoking the acrylamide pathway (Fig. $13 \& 14$ ).

Since reducing sugars and free amino acids are precursors of flavour components and of browning formed in the Maillard reaction (Roe et al., 1990 \& Whit-field, 1992) which means that acrylamide is generated parallel with falvours and browning. Storage of potatoes at temperatures below $8-10^{\circ} \mathrm{C}$ induced a strong increase in sugar content. The phenomenon is commonly known as "lowtemperature sweetening" (Coffin et al., 1987). Potatoes of the cultivar Erntestolz stored at $4^{\circ} \mathrm{C}$ for 15 days exhibited an increase in reducing sugars from 80 to 2250 $\mathrm{mg} / \mathrm{kg}$ (referring to fresh weight). As a consequence, the potential of acrylamide formation at $120^{\circ} \mathrm{C}$ rose by a factor of 28 (Biederman et al., 2002). Long-term storage at higher temperatures may, however, be a problem concerning sprouting in late spring/early summer, which usually requires the applications of sprouting inhibitors (Smith, 1977).
Yasuhara et al. (2003) investigated acrylamide formation in browning model systems (Fig. 14). Asparagine alone produced acrylamide via thermal degradation at the level of $0.99 \mu \mathrm{g} / \mathrm{g}$ of asparagine. When asparagine was heated with triolein-which produced acrolein at the level of $1.82 \pm 0.31(\mathrm{n}=$ 5) $\mathrm{mg} / \mathrm{L}$ of headspace by heat treatment, acrylamide was formed at the level of 88.6 $\mu \mathrm{g} / \mathrm{g}$ of asparagine. When acrolein gas was sprayed onto asparagine heated at $180^{\circ} \mathrm{C}$, a significant amount of acrylamide was formed (114 $\mu \mathrm{g} / \mathrm{g}$ of asparagine). On the other hand, when acrolein gas was sprayed onto glutamine under the same conditions, only a trace amount of acrylamide was formed $(0.18 \mu \mathrm{g} / \mathrm{g}$ of glutamine). Relatively high levels of acrylamide $(753 \mu \mathrm{g} / \mathrm{g}$ of ammonia) were formed from ammonia and acrolein heated at $180^{\circ} \mathrm{C}$ in the vapour phase. The reaction of acrylic acid, which is an oxidation product of acrolein and ammonia, produced a high level of acrylamide (190000 $\mu \mathrm{g} / \mathrm{g}$ of ammonia), suggesting that ammonia and acrolein play an important role in acrylamide formation in lipid-rich foods. Acrylamide can be formed from asparagine alone via thermal degradation, but carbonyl compounds such as acrolein, promote its formation via a browning reaction.

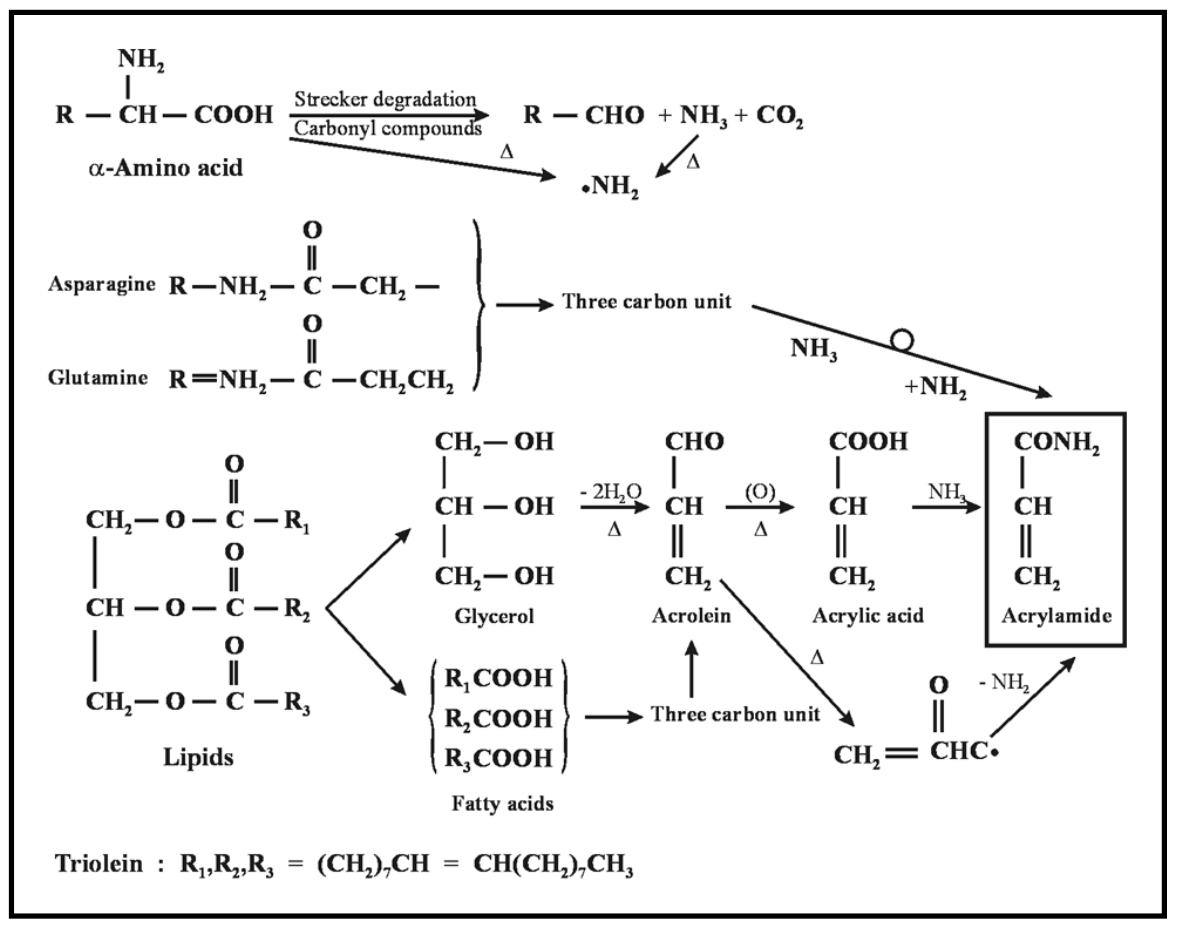

Fig. 12: Hypothesized formation mechanisms of acrylamide from an amino acid and a lipid Ref. Yasuhara et al. (2003) 


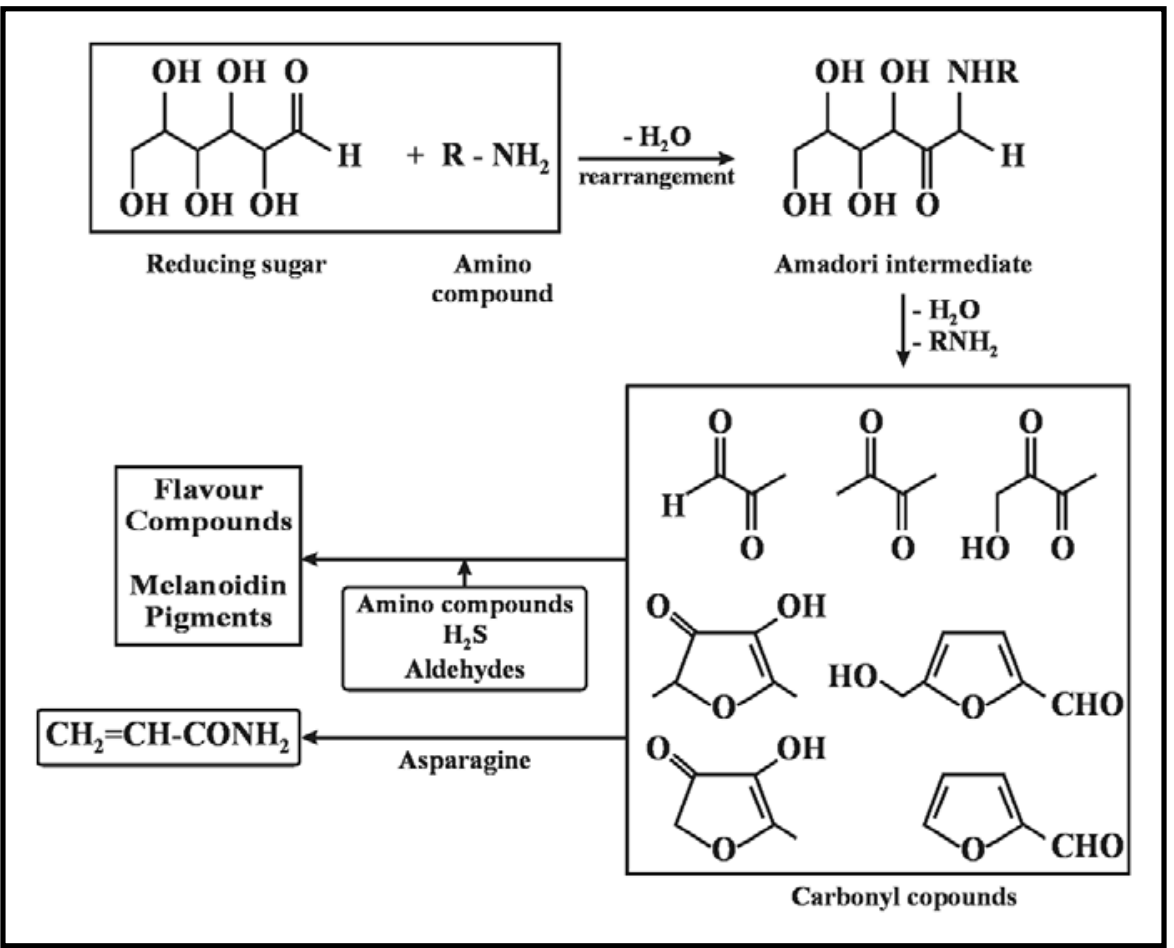

Fig. 13: Possible relationship between Maillard reaction and formation of acrylamids Ref. Mottram and Wedzicha (2003)

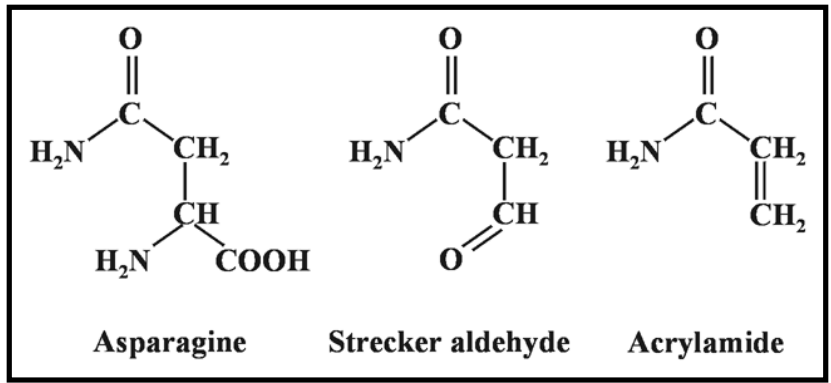

Fig. 14: Possible role of Maillard reaction in acrylamide formation Ref. Mottram and Wedzicha (2003)

\section{3 - Effects of processing conditions on for- mation of acrylamide in foods:}

A hypothesis that acrylamide is formed in cooking was confirmed in animal experiments by verification of the identity of the acrylamide adduct in haemoglobin $(\mathrm{Hb})$. This was comprehensively approved by MS/MS analysis and the demonstration that the increased adduct levels were compatible with expectation from the contents of acrylamide determined in fried feed (Tareke et al., 2000).

Factors that affect acrylamide formation in different foodstuffs were investigated by Tareke et al. (2002). They investigated the influence of the cooking method with regard to acrylamide formation by comparing heating in a frypan, boiling and microwave heating. Fig. (15) shows measured acrylamide levels in fried hamburgers from the initial experiment with frying of hamburger meat at different temperatures. A significant dependence of acrylamide formation on temperature was demonstrated. In raw hamburgers, the acrylamide content was below the detection level $(5 \mu \mathrm{g} / \mathrm{kg})$. Meanwhile, the level of acrylamide was below the detection level ( 5 $\mu \mathrm{g} / \mathrm{kg}$ ) in boiled or raw beef and potato, in boiled fish, as well as in broth from the boiling tests. Following controlled heating, protein rich foods exhibited acrylamide concentration between 5 and $50 \mu \mathrm{g} / \mathrm{kg}$, with lower levels in fish. In the experiments with heating of carbohydrate-richfoods, relatively higher contents of acrylamide (150-1000 $\mu \mathrm{g} / \mathrm{kg})$ were measured. On the other hand, following microwave heating of fish and potato, no detectable levels of acrylamide were found in 
fish. Detailed data are given in Table 2 and illustrated in Fig. (15).

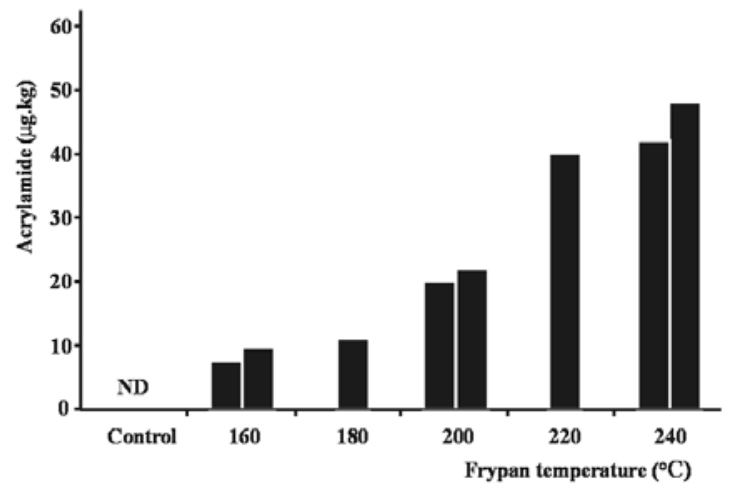

Fig. 15: Acrylamide concentrations $(\mu \mathrm{g} / \mathrm{kg}$ ) in hamburgers (single and duplicate samples) dependent on fry pan temperatures ( 3 min of frying time on each side).

Ref.: Tareke et al .( 2002)

Analysis of some commercially prepared foodstuffs, mainly potato products, gave results compatible with those obtained after cooking under laboratory conditions (Table 2 and Fig. 15). French-fried potatoes and potato crisps exhibited relatively high levels of acrylamide (median values of $422 \mu \mathrm{g} / \mathrm{kg}$ $(\mathrm{n}=5)$ and $1739 \mu \mathrm{g} / \mathrm{kg}(\mathrm{n}=6)$, respectively\}, (Fig 16). Large variations of acrylamide levels in similar foods were observed and could also be expected when prepared commercially, because of differences in heating time, etc. This was observed, particularly for French fries and potato crisps. There were also variations between samples of fried potatoes. It should be noted that the commercially fried potato pancake contained not only grated potato (as in the laboratory frying) but also in mixed with egg, milk and flour (Fig. 16), which might have had an influence on acrylamide formation during heating (Tareke et al. 2002). Boiling of potatoes prior to frying seemed to reduce the formation of acrylamide (tested in parallel experiments).

\section{4- Absorption and distribution of acryla- mide:}

Acrylamide is absorbed by animals and humans via ingestion, inhalation or through the skin. Numerous studies, both in vivo and in vitro, have been conducted to evaluate the potential dermal absorption of acrylamide. No studies attempted to directly quantify absorption of acrylamide following oral or inhalation exposure (Miller et al. 1982). Extensive efforts have been made to assess human exposure to acrylamide by monitoring several metabolites exerted in the urine as well as products resulting from biological alkylation by acrylamide. Distribution and excretion studies indicated that following oral administration in rats; acrylamide was readily absorbed (Miller et al., 1982; Sumner et al., 1997), this was found in a study, where rats received a single dose $(20 \mathrm{mg} / \mathrm{kg} /$ day $)$ of acrylamide or by intraperitioneal injection $(50 \mathrm{mg} / \mathrm{kg} /$ day). Although no quantitative estimate of oral absorption can be made based on the results of this study, a comparison of the dose-adjusted area under the plasma concentration curves between the two routes of exposure can provide a qualitative estimate of oral absorption (Barber et al., 2001). This comparison also indicated that systemic absorption following oral exposure appeared to be slightly less than observed following intraperitioneal administration of acrylamide, with greater conversion to glycidamide following oral exposure.

Results from in vivo studies conducted in rats indicated that dermal absorption ranged from approximately 14 to $61 \%$ of the applied dose (Sumner et al., 1997; Tareke et al., 2000). The in vitro results obtained from rat, pig and human skin samples showed that 42 to $93 \%, 93$ to $94 \%$ and 27 to $33 \%$ of the applied acrylamide dose was absorbed for each species, respectively (Tareke et al., 2000).

Animal studies have shown that acrylamide and glycidamide are widely distributed in all tissues of the body (FAO/WHO, 2002). Following oral admini-stration of $1 \mathrm{mg}$ acrylamide/kg body weight, distribution of acrylamide in dogs and bigs was great in the muscle tissue, ranging from approximately 30 to $50 \%$ of the administered dose (Miller et al., 1982).Further more, in dogs, the greatest radioactivity following muscle tissue was observed in the liver (14\%), while in the big it was observed in the gastrointestinal tract $(20 \%)$, this may reflect slower absorption in the pig (Anonymous, 2002b). Studies on rats (Sumner et al., 1999) and mice (Carlson et al., 1986), evaluated the distribution of acrylamide following dermal application of 100 to $160 \mathrm{mg} /$ acrylamide $/ \mathrm{kg}$ body weight. At $24 \mathrm{hr}$ post exposure, acrylamide levels were higher in the skin for both species. In the rat, acrylamide concentrations of approximately $1 \mu \mathrm{mol} / \mathrm{g}$ tissue were reported in red blood cells. The only other location where the concentration was higher was at the site of application (e.g. the skin, $4 \mu \mathrm{mol} / \mathrm{g}$ tissue) (Carlson et al., 1986; Sumner et al., 1999). A similar pattern was observed in the mouse following dermal application of acrylamide although no measurement of acrylamide in the blood was conducted. 
Table 2 : Levels of acrylamide analyzed in single samples of different foodstuffs (micrograms per kilogram of heated foodstuff) ${ }^{\mathrm{a}}$.

\begin{tabular}{|c|c|c|c|c|}
\hline \multirow{2}{*}{ Fried food } & \multicolumn{4}{|c|}{ Laboratory-prepared foods } \\
\hline & A-1 & A-2 & A-3 & median \\
\hline Beef, minced & $20 ; 22$ & & $15 ; 15 ; 17$ & 17 \\
\hline Chicken, minced & & $16 ; 41$ & & 28 \\
\hline Cod, minced & $<5 ;<5$ & 11 & & \\
\hline Pork, minced & 52 & & & \\
\hline Soymeal beef & $15 ; 16$ & & & 16 \\
\hline Potato, grated & $730 ; 780$ & 447 & $394 ; 310$ & 447 \\
\hline Potato, boiled, mashed & & & $201 ; 144$ & 172 \\
\hline Beetroot, grated & & $810 ; 890$ & & 850 \\
\hline Spinach, grated & & 112 & & \\
\hline Microwave-heated food & & A-2 & & median \\
\hline Cod & & $<5 ;<5$ & & \\
\hline Potato, grated & & $455 ; 650$ & & 551 \\
\hline Boiled food & A-2 & A-4 & A-5 & median \\
\hline Potato (boiled or raw ${ }^{b}$ ) & $<5 ;<5$ & $<5 ;<5$ & $<10^{* b}$ & \\
\hline Potato, broth & $<5 ;<5$ & $<5 ;<5$ & & \\
\hline Beef (boiled or raw ${ }^{b}$ ) & $<5^{\mathrm{b}} ;<5^{\mathrm{b}}$ & $<5 ;<5$ & $<5 ;<5$ & \\
\hline Beef, borth & & $<5$ & $<5 ;<5$ & \\
\hline Cod & $<5 ;<5$ & & & \\
\hline Cod, borth & $<5 ;<5$ & & & \\
\hline
\end{tabular}

\begin{tabular}{|c|c|c|c|c|}
\hline Food & A-3 & A-4 & A-5 & median $^{c}$ \\
\hline Hamburger & & & $14 / 14^{*} ; 23 / 23^{*}$ & 18 \\
\hline Pork (fried) & 45 & & & \\
\hline “flau” sausage (fried) & & $<5$ & & \\
\hline French fries & 732 & $314 ; 327$ & $661 / 684^{*} ; 424^{*}$ & 424 \\
\hline Potato pancake & 167 & & & \\
\hline Potato cubes & 313 & & & \\
\hline Potato crisps & & $\begin{array}{l}1300 ; \\
1800 / 1678^{*}\end{array}$ & $\begin{array}{l}1538 / 1544^{*} ; \\
2148^{*} ; 3897^{*} ; \\
1496^{*}\end{array}$ & 1739 \\
\hline Crispbread, three types & 208 & & $37^{*} ; 1731^{*}$ & 208 \\
\hline Bread, white & & $13^{\mathrm{d}} ; 53^{\mathrm{d}}$ & $49^{*}$ & \\
\hline Rye & & & $<5^{*}$ & \\
\hline Oat & & & $7.3^{*}$ & \\
\hline \multicolumn{2}{|c|}{ Beer (dark and larger, three types) } & & $<5 ;<5 ;<5$ & \\
\hline
\end{tabular}

${ }^{\text {(a) }}$ A-1-A-5 denote different analytical series. Analysis with GC-MS; analysis with LC-MS/MS marked with an asterisk(*). Acrylamide concentrations determined in the samples by both GC-MS and LCMS/MS have been separated by a slash $(/) .{ }^{\left(b^{b}\right.}$ Sample before boiling. Samples of raw beef from the first experiment (Figure 4). ${ }^{(\text {c) }}$ For repeated analysis of the same sample. Separated by/ mean values are used. (') before and after toasting.

Ref. Tareke et al. (2002). 


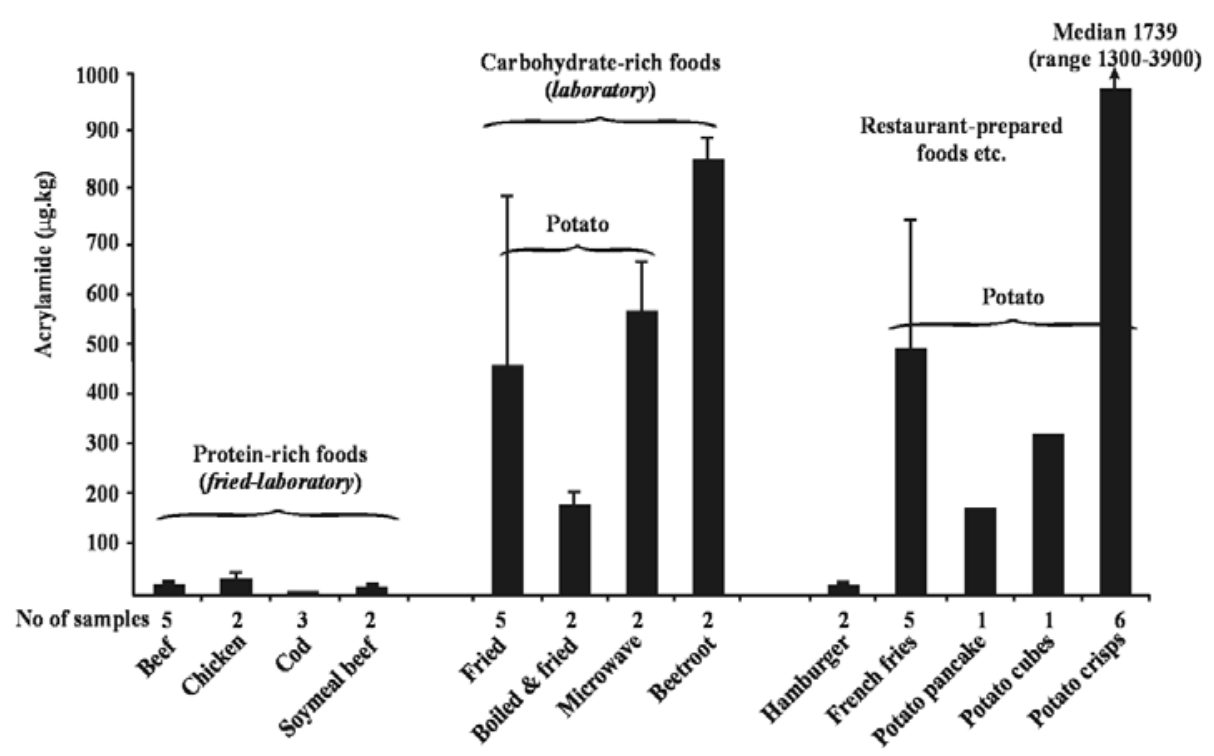

Fig. 16: Acrylamide concentrations $(\mu / \mathrm{kg})$ (median and range) in laboratory-heated and commercial foodstuffs.

Ref.: Tareke et al. (2002).

Animal studies have shown that acrylamide and glycidamide are widely distributed in all tissues of the body (FAO/WHO, 2002). Following oral admini-stration of $1 \mathrm{mg}$ acrylamide $/ \mathrm{kg}$ body weight, distribution of acrylamide in dogs and bigs was great in the muscle tissue, ranging from approximately 30 to $50 \%$ of the administered dose (Miller et al., 1982).Further more, in dogs, the greatest radioactivity following muscle tissue was observed in the liver (14\%), while in the big it was observed in the gastrointestinal tract $(20 \%)$, this may reflect slower absorption in the pig (Anonymous, 2002b). Studies on rats (Sumner et al., 1999) and mice (Carlson et al., 1986), evaluated the distribution of acrylamide following dermal application of 100 to $160 \mathrm{mg} /$ acrylamide $/ \mathrm{kg}$ body weight. At $24 \mathrm{hr}$ post exposure, acrylamide levels were higher in the skin for both species. In the rat, acrylamide concentrations of approximately $1 \mu \mathrm{mol} / \mathrm{g}$ tissue were reported in red blood cells. The only other location where the concentration was higher was at the site of application (e.g. the skin, $4 \mu \mathrm{mol} / \mathrm{g}$ tissue, Carlson et al., 1986; Sumner et al., 1999). A similar pattern was observed in the mouse following dermal application of acrylamide although no measurement of acrylamide in the blood was conducted.

In another study on rats following intravenous administration of 10,50 and 100 $\mathrm{mg} / \mathrm{kg}$ acrylamide to rats, the majority of the administered acrylamide was found in the red blood cells at most time points (Miller et al., 1982). The distribution of administered acrylamide to the blood is related to the ability of both acrylamide and its metabolite glycidamide to bind with haemoglobin to form adducts (Calleman et al., 1990).

\section{5 - Metabolism of acrylamide :}

The major metabolite formed via the cytochrome P450 pathway is glycidamide (Miller et al., 1982; Sumner et al., 1999). Species differences in the formation of this metabolite has been observed, with acrylamide converted to glycidamide to a greater extent in the mouse than in the rat, based on urinary metabolites (Sumner et al., 1997).

Once absorbed, acrylamide may conjugate by glutathione-S-transferase (GST) to Nacetyl-S-(3 amino-3-oxopropyl) cysteine or it may react with cytochrome $\mathrm{P} 450$ to produce glycidamide (Miller et al., 1982). Conjugation to glutathione reduce (GSH) catalyzed by GST and excretion as mercapturic acid is a major pathway for the metabolism of acrylamide. The mercapturic acid is excreted in the human urine. The mercapturic acid isolated from the urine of workers exposed to acrylamide could be measured by an HPLC procedure with a detection limit of $1 \mathrm{p} \mathrm{mol}$ (Wu et al., 1993). The urine of mice and rats exposed to acrylamide also contained several other cysteine metabolites. 
The major metabolite formed in both rat and mouse is N-acetyl-S-(3-amino-3-oxopropyl) cysteine, accounting for approximately $70 \%$ of the urinary metabolites observed in rats and $40 \%$ of those observed in mices (Sumner et al., 1997).

The GSH concentration in the human liver is high, ranging from 3 to $5 \mu \mathrm{mol} / \mathrm{g}$ of liver. Conditions that can decrease GSH levels and hence increase the toxicity of acrylamide at much lower exposure include (a) malnutrition associated with consumption of diets low in the sulfur amino acids cystine and methionine (Khanna et al., 1988; 1992), (b) oxidative stress, which may result in oxidation of GSH to GSSG, and (c) liver damage associated with alcoholic hepatites and other malignant disorders. According to Odland et al., (1994), the rate of protein synthesis as well as GSH levels of neuroblastoma cells decreased on exposure to acrylamide. The resulting depletion GSH could lead to less protection of cell membranes against oxidative stress.

On the basis of the available data on the proportion of various metabolites in the urine of the rat, the metabolism of acrylamide via cytochrome $\mathrm{P} 450$ is described by a $\mathrm{V}_{\max }$ of $1.6 \mathrm{mg} / \mathrm{h} / \mathrm{kg}$ and $\mathrm{a} \mathrm{k}_{\mathrm{m}}$ of $10 \mathrm{mg} / \mathrm{l}$ and via glutathione-S-transferese catalyzed conjugation to GSH (Kirman et al., 2003).

Several metabolic studies indicated that liver, kidney, brain and erythrocyte GST have significant binding capacity with acrylamide. The liver GST is 3 times more efficient in conjugating acrylamide as compared to brain GST in the rat (Aanonymous, 2002b). Additional studies on rats indicate that acrylamide may inhibit GST, resulting in an increase of glycidamide by the cytochrome $\mathrm{P} 450$ pathway (Odland et al., 1994).

The kinetic analysis suggests that among the potential modes of action considered reaction with SH group appear to be the most biologically relevant (Miller et al., 1982; Kirman et al., 2003). A parallel metabolic pathway involves epoxide hydrolasecatalyzed hydration of glycidamide to 2,3dihydroxypropionamide (Kirman et al., 2003).

\section{6 - Toxicity of acrylamide : \\ (a) Neurotoxicity :}

Neurotoxicity is the only recognized adverse effect of oral acrylamide in humans. Multiple studies have been conducted to asses neurotoxic effects of acrylamide in occupationally-exposed workers in factories manufacturing acrylamide or using acrylamide in production. Workers exposed to acrylamide exhibited symptoms of peripheral neuropathy suggesting that the compound is a human neurotoxin (He et al., 1989; Hagmar et al., 2001; FAO/WHO, 2002). Occupational exposure of Swedish tunnel workers to grouting agent containing acrylamide and $\mathrm{N}$ methyloacrylamide resulted in mild and reversible peripheral nervous system symptoms (Hagmar et al., 2001).

Acrylamide and N-methylolacrylamide differ in their ability to form haemoglobin adducts in rats (Fennell et al., 2003). A correlation was demonstrated between levels of haemoglobin adducts and degree of peripheral neuropathy. These studies concluded that exposures greater than $1 \mathrm{mg} / \mathrm{kg} /$ day were associated with peripheral neuropathy.

In a study made by Tareke et al. (2002), haemoglobin adducts was formed in vivo through Michael addition of acrylamide to the amino terminal valine, of haemoglobin and detached from the protein as derivatives of N-(2-carbonylethyl) valine. The same adduct has also been observed in studies of laboratory animals treated with acrylamide and in animals with accidental exposure to acrylamide. In a previous study with rats fed on laboratory feed, an intake of acrylamide was measured as an increase of acrylamide adducts to haemoglobin, the incremental adduct level being shown to be compatible with the acrylamide in the feed.

Seventy one workers between the ages of 17 to 41 exposed to acrylamide by industrial production and had been employed from 1 to 18 months and fifty one unexposed workers served as a reference group, were compared . Approximately $73 \%$ of the exposed workers exhibited symptoms of acrylamide poisoning (He et al., 1989).

In 1989 in a South Africa factory in which polyacrylamide flocculants were manufactured, five of peripheral neuropathy were diagnosed. These cases led to an industrial hygiene and neuralgic evaluation of the remaining 66 exposed and unexposed workers in that factors (Anonymous, 2002b). Humans and animals develop a low grade peripheral neuropathy with advance of age, which are more susceptible to acrylamide neuropathy.

The Neurotoxicity of acrylamide has been extensively studied in various animal models including, rats, mice, monkeys, dogs and cats. Overt signs of neurotoxicity were 
consistent among species. However, while some studies evaluated only overt neurotoxicity (grip strength or leg splay), other studies examined morphological or biochemical changes in nerve tissues (Anonymous, 2002b). Early studies showed that acrylamide induced neurophathological changes (peripheral distal axonopathy) in laboratory animals (Miller \& Spencer, 1985), whereas more recent studies show that nerve terminals are the initial sites for lesions with axonopathy as a conditional effect related to long-term lowdose intoxication (LoPochin, 2002).

In general, cumulative dose is important when overt neurotoxicity is evaluated. In rats exposed via the oral route, single dose of $100 \mathrm{mg} / \mathrm{kg}$ were reported to result in alterations in grip strength and motor function (Anonymous, 2002b). With short term multiple exposures, clinical signs of toxicity and decreased motorfunction were reported in rats following administration of $25 \mathrm{mg} / \mathrm{kg} /$ day for 21 days (Wise et al., 1995). Also, feeding of high amount of acrylamide to rats (21 $\mathrm{mg} / \mathrm{kg} /$ day at $7,14,28$ and 38 days) resulted in degeneration of the brain stem, cerebellum and spinal cord (Friedman et al., 1995; Wise et al., 1995), whereas long-term consumption of low levels of acrylamide contribute to the causes of Alzaheimer's or other degenerative diseases of the human brain.

In a subchronic toxicity study, effects on rotorad performance were observed at doses around $14.5 \mathrm{mg} / \mathrm{kg}$ (Tyl \& Friedman, 2003) and hindlinb splay was increased in rats that received $9 \mathrm{mg} / \mathrm{kg}$. They also reported an increase in morphological changes following electron microscopic examinations of peripheral nerves of rats that received $1 \mathrm{mg} / \mathrm{kg} /$ day for 90 days. These effects were reversible after 144 days of recovery, with the exception of the group that received $20 \mathrm{mg} / \mathrm{kg} / \mathrm{day}$ (Friedman et al., 1995; Anonymous, 2002b).

In mice, decreases in rotorad performance were reported at doses $9 \mathrm{mg} / \mathrm{kg}$ (Bull et al., 1984). The administration of 10 $\mathrm{mg} / \mathrm{kg} /$ day to monkeys for 45 to 60 days resulted in losses of motor function (Granath et al., 2001). Overt evidence of neurotoxicity and decreased nerve conduction velocity was reported in cats that received doses of 15 $\mathrm{mg} / \mathrm{kg} /$ day for up to 4-16 weeks.

Recent studies of LoPachin et al. (2002a) measuring multiple neurological parameters across two intoxication schedules (21 and 50 $\mathrm{mg} / \mathrm{kg}$ ) have indicated that acrylamide produces cumulative neurotoxicity. Research from other laboratories suggests that this cumulative phenomenon applies to dose-rates significantly lower than those used in the aforementioned study.

According to Godin et al., (2002), seven beef cattle accidentally exposed to acrylamide while grazing, exhibited clinical signs of impaired nerve function in hindlegs, irritability and sensitivity to touch. The severity of neurological symptoms correlated with levels of Hb-acrylamide adducts. Although measurement of $\mathrm{Hb}$-acrylamide adducts appears to be an accurate biomaker for acrylamideinduced neurotoxicity, the nature of the cellular SH components of nerve tissues involved have not been elucidated. These could include both nonprotein $\mathrm{SH}$ groups as well as protein-bound SH group (Martenson et al., 1995).

Srivistava et al., (1986) showed that acrylamide inhibit the action of brain GST and reduced the levels of brain GSH. Related studies by Cupta \& Abou-Donia (1996), suggest that acrylamide interacts with tubulin and other cytoskeleton proteins, resulting in accumulation of microfilaments as well as increases of brain and spinal cord neurofilament proteins.

LoPochin et al. (2002a, b) proposed that the nerve terminal is the primary site of acrylamide action leading to inhibition of neurotransmission at central and peripheral synapses is based on adduct formation between acrylamide and cysteine-rich terminal proteins that mediate fusion of membrane during exocytosis. Acrylamide is a weak thiolalkylating compound; therefore, it can be administered on a subchronic daily basis at relatively high dose rates.

A possible explanation for the neurotoxicity of acrylamide is that it is a bipolar molecule, where in the $\mathrm{CH}_{2}=\mathrm{CH}$ part can undergo hydrophobic interactions and the $\mathrm{CONH}_{2}$ part, hydrogen bonding interactions with cell components. This property may enhance its ability to alter cell membrane structures and accelerate its diffusion and penetration to nerve terminal sites associated with normal function of the nervous system . Among these interactions are hydrogen bonding with $\mathrm{H}_{2} \mathrm{O},-\mathrm{CO}-\mathrm{NH}-,-\mathrm{COO}^{-}$of aspartic and glutamic acid residues and positively charged molecules forming charged, noncovalent intermediates (Friedman \& William, 1977), charge transfer interaction with tryptophan and nucleic acids may also influence this process. 
The SH groups associated with components of the peripheral nervous system fall into the highly reactive category (Friedman, 1973). This would explain the apparent high affinity of these groups for acrylamide. One factor that would be expected to influence rates, is the extent of ionization of the $\mathrm{SH}$ groups in tissues to facilitate future studies, it is also instructive to examine electronic and charge effects, which may influence reaction rates of $\mathrm{SH}$ and $\mathrm{NH}_{2}$ groups with acrylamide. The mechanism of formation of the respective transition states differs in several features that energetically favour reaction of the ionized $\mathrm{SH}$ group (i.e., $\mathrm{S}$, mercaptide ion) more than that of the $\mathrm{NH}_{2}$ group (Friedman, 1973). Model studies show that both groups have to approach the double bond of acrylamide almost at right angles to the plane of the molecule but the $\mathrm{NH}_{2}$ group has to assume a more restricted orientation than the sulfur atom to form the transition state.

\section{(b) Reproductive toxicity :}

Acrylamide has been evaluated for reproductive toxicity in multigenerational studies in rats and mice (Tyl et al., 2000). It was reported to induce dominant lethal mutations in spermantids (chromosome damaging effects) of rats and mice and is thus considered to be a mammalian germ cell mutagen (Shelby et al., 1987; Tyl et al., 2000). Although it is not active in the in vitro Ames test, acrylamide does elicit mutagenic effects in stem cell spermatogonia (Dearfield et al., 1995). Studies by Paulsson et al. (2003) support the view that in the mouse, glycidamide is the predominant genotoxic factor in acrylamide expsosure.

Acrylamide administered in drinking water $(50-200 \mathrm{ppm})$ to female and male rats prior to breeding and through the gestation and lactation period (up to 10 weeks) produced disruptions in mating, interference with sperum ejaculation, depression in body weight gain and food intake and depression in pup body weight at birth and weight gain during lactation (Zenick et al., 1986). Feeding acrylamide to rats at levels of $5-20 \mathrm{mg} / \mathrm{kg} /$ day induced neurological manifestations lasting for 30-90 days. At neurotoxic doses, acrylamide also acts as a reproductive toxicant, as evidenced by reduced fertility rates, increased resportions of fetuses and reduced litter size of pregnant females and by formation of abnormal sperm and decreased sperm count in males (Sakamoto \& Hashimoto, 1986. Chapin et al., 1995).
In another study by Tyl et al. (2000) at $15 \mathrm{mg} / \mathrm{kg}$ /day of acrylamide, signs of neurotoxicity and changes in copulatory behavior were noted as well as decreased in sperm motility. At these doses in both mice and rats, acrylamide resulted in decreases in fertility in addition, changes in pre-and postimplantation loses (Paulsson et al., 2003). Some data suggest that exposure of females to acrylamide may contribute to reproductive toxicity. A delay is vaginal potency was noted in offspring females treated by 14 $\mathrm{mg} / \mathrm{kg} /$ day for 70 days mated to untreated males suggesting that perimatal exposure of female pups might result in subtle alternations in the estrogen/progesterone balance (Zeinck et al., 1986). Although acrylamide caused toxicity in the pregnant mother, there was no evidence for acrylamide-induced neurotoxicity in the offspring of F1 males.

The molecular mechanisms of reproductive toxicity could be the result of alkylation of SH groups in the sperm nucleus and tail, depletion of GSH and DNA damage in the testis (Dearfield et al., 1995). To separate neurotoxicity from reproductive effects, Tyl et al. (2000), designed a two-generation reproductive study with neurotoxic end-points. The results show that in rats, neurotoxicity and reproductive toxicity were affected by different doses of acrylamide in drinking water. Evidently, neurotoxicity appears to be the cause or is a major contributor to reproductive toxicity. The available evidence is consisted with similar mechanisms leading to both fertility and neurotoxic endpoints. Dominant lethality effects, with different dose-response profiles, appear to operate by a mechanism involving chromosomal damage during spermatogenesis in the tests (Tyl et al., 2000).

Otherwise, the roles of nutrients (proteins, carbohydrates, fats, vitamins and minerals) on the severity of acrylamide toxicity as well as possible additive and synergistic effects of heat-induced food mutagens and carcinogens and dietary acrylamide are largely unkown.

\section{(c) Carcinogenicity of acrylamide :}

On the basis of numerous studies, the International Agency of Research on Cancer (IARC, 1994) has classified acrylamide as "Probably carcinogenic to humans", as is apparently also N-methyloloacrylamide. Epidemiological investigations have been unable to either confirm or disprove human carcinogenicity of acrylamide, even in occupationally exposed cohorts (IARC, 1994, NTP, 
1998). Thus, human data useful for cancer risk estimation are not available. The magnitude of the cancer risk from acrylamide has therefore been assessed from animal experiments (two-years tests with rats) (IARC, 1994; Friedman et al., 1995). Acrylamide is carcinogenic in laboratory rats in standard 2 years bioassays, producing increased incidences of a number of benigen and malignant tumors identified in a variety of organs, e.g. thyroid and adrenals. Furthermore, experimental animal studies showed that acrylamide could induce an increased incidence of cancers in brain central nervous system and reproductive organs of mouse (Bull et al., 1984).

According to WHO, a life long (70 years) intake of $1 \mu \mathrm{g}$ of acrylamide per day would be associated with a life time cancer risk of $1 \times 10^{-5}$ (WHO, 1996). The drinking water guideline of WHO for acrylamide as 1 $\mu \mathrm{g} /$ day at a consumption of $21 /$ day. A lifetime oncogenicity study in rats administered acrylamide in drinking water at $0-2$ $\mathrm{mg} / \mathrm{kg}$ /day showed increases in the incidence of tumors in several organs, especially at the higher doses (Friedman, et al., 1995).

The mutagenic and carcinogenic factor in acrylamide exposure is assumed to be the epoxy metabolite; glycidamide (Paulson et al., 2003). Acrylamide does not induce gene mutations in bacteria, but the epoxide metabolite does in the absence of metabolic activation. Also, acrylamide was unable to induce unscheduled DNA synthesis (UDS) in rat hepatocytes, whereas glycidamide induced UDS in human mammary cells, with equivocal results in rat hepatocytes (Hashimoto \& Tanii, 1985; Dearfield et al., 1995). Glycidamide was 100-1000 times more reactive with DNA than was acrylamide.

\section{7- Determination of acrylamide :}

Castle et al. (1991) has determined acrylamide monomer in hydroponically grown tomato fruits by capillary gas chromatography-mass spectrometry (GC/MS). Tomato fruits were analysed by extraction of the aqueous phase, bromination, silica gel cartridge cleanup and capillary GC-MS determination by selected ion monitoring. The recovery of the method was $26-62 \%$ but losses were compensated for by use of 2,3-dibromo2-dimethylpropionanide as internal standard.

A rapid and convenient procedure for the determination of acrylamide in foodstuffs was described by Brandl et al., (2002). Sample extraction was performed by Accelerated Solvent Extractor (ASE), using dichloromethane (DCM) containing 2\% ethanol.
Acrylamide was determined by HPLC, using Dionex ASE 200, Thermo Quest TSQ 7000 (Triple quadrupole mass spectrometer) by using atmospheric pressure chemical ionization (APCI), HPLC: Shimadzu LC 10. It is worth to mention that it was necessary to add to all samples inclusively the blank the same amount of water because it may act as a modifier during the ASE procedure. The calibration graph of standard solutions in water showed excellent linearity $\left(\mathrm{R}^{2}=0.999\right)$. The limit of detection was determined at a level of $10 \mathrm{ng} / \mathrm{ml}^{-1 .}$ Applying the aforementioned conditions, nearly all of the target foodstuffs could be analyzed.

Acrylamide levels in foodstuffs were analyzed by an improved GC-MS method after bromination of acrylamide and by a new method for measurement of the underivatized acrylamide by liquid chromatography-mass spectrometry (LC-MS) using the MS/MS mode. For both methods, the reproducibility, given as coefficient of variation, was $5 \%$ and the recovery close to $100 \%$. For the GC-MS method, the achieved detection level of acrylamide was $5 \mu \mathrm{g} / \mathrm{kg}$ and for LC-MS/MS method, $10 \mu \mathrm{g} / \mathrm{kg}$. The analytic values obtained with the LC-MS/MS method were $0.99(0.95-1.04 \%, 95 \%$ confidence interval) of the GC-MS values. The LCMS/MS method is simple and preferable for most routine analysis. Taken together, the various analytic data should be considered as proof of the identity of acrylamide (Tareke $e t$ al., 2002).

Yasuhara et al., (2003) analyzed the acrylamide formed in browning model systems using a gas chromatograph with a nitrogen phosphorus detector (NPD). The detection and quantitative limits of GC/NPD were 0.20 and 0.67 ng., respectively.

Acrylamide in food products-chiefly in commercially available potato chips, potato fries, cereals and bread was determined by liquid chromatography-tandem mass spectrometry (LC-MS/MS). Samples were homogenized with water/dichloromethane, centrifuged and filtered through a $5 \mathrm{KD}_{\mathrm{a}}$ filter. The filtrate was cleaned up on mixed mode, anion and cation exchange (Oasis MAX and $\mathrm{MCX}$ ) and carbon (Envirocarb) cartridges. Analysis was done by isotope dilution $\left(\left\{\mathrm{D}_{3}\right\}\right.$ or $\left\{{ }^{13} \mathrm{C}_{3}\right\}$ acrylamide) electrospray LCMS/MS using a $2 \times 150 \mathrm{~mm}$ (or $2 \times 100 \mathrm{~mm}$ ). Thermo Hyper Carb column was eluted with $1 \mathrm{mM}$ ammonium formate in $15 \%$ (or $10 \%$ for the $2 \times 100 \mathrm{~mm}$ column) methanol (Becalski et al., 2003).

Biedermann et al., (2003) described two GC/MS methods for the analysis of acryla- 
mide in foodstuffs. The steps of the first method are as follows :

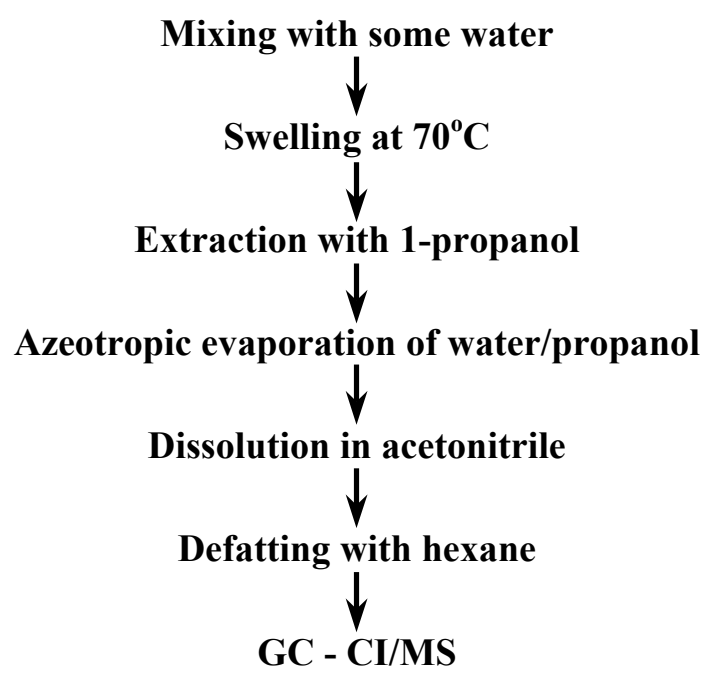

The steps of the second method are as follows:

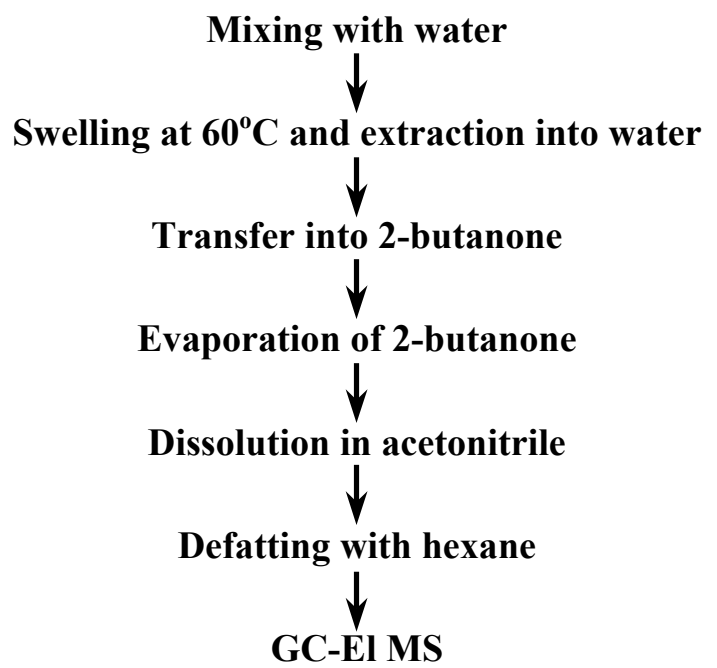

\section{8 - Conclusions}

In the light of the report of $\mathrm{FAO} / \mathrm{WHO}$ (2002) working group, the following main points were explored:

Full list of Proposed Research (not ranked by priority):

1. Need data on the quantity of free asparagine on a dried weight basis for various foods (database-variety, crop conditions, storage). Need data on the quantity of glucose, fructose (and other sugars) and amino acids other than asparagine for various foods.

2. Define the direct correlation of asparagine to acrylamide production in foods.

3. Investigate the effects of production of acrylamide in meats from methionine (and cystine).
4. Time/temperature/pH moisture/surface area-mass mapping and kinetics of asparagine/carbonyls reaction in various matrices. may include mathematical modeling.

5. Does irradiation of foods containing free asparagine and carbonyls result in the formation of acrylamide?

6. Pressure processing effects on the formation of acrylamide.

7. Investigate the purity of amino acids (e.g. glutamine or aspartic acid) used in model systems for studying the mechanism of formation of acrylamide.

8. What is the effect of fermentation on the quantities of asparagine in foods and subsequently on acrylamide production?

9. Do acrylamide formation intermediates, (e.g. the Schiffs bases), form during storage of potatoes as the asparagine and glucose levels go up?

10. Other mechanisms of acrylamide formation, i.e. directly from protein.

Recommendations for Acrylamide Mitigation Research :

1. For potatoes (and perhaps other foods) storage conditions should be investigated for ultimate effect on acrylamide formation.

2. What are the kinetics of acrylamide destruction under various conditions?

3. Investigate mixed amino acids, i.e. do competitive reactions and/or scavenging reactions reduce the free acrylamide?. Is ammonium ion (i.e. ammonium carbonate or ammonium bicarbonate) a possible competitive agent ? Glutathione/Cystine to promote sulfhydryls-disulfide interchange to provide scavengers?

4. Reduction of free amino acids in matrices by yeast or other organisms and mechanisms.

5. Hydrolyzed nucleic acids as a scavenging agents for acrylamide.

6. Asparaginase conversion of free asparagines to asparatic acid. Can asparagine be converted/transformed to other compounds of lesser concern, i.e. esters or other derivatives?

7. Modification of biosynthesis pathways to control the formation of free asparagine and/or glucose (Horticulture, breeding, genetic modification). Is asparagine essential for the survival of the plant?

8. Modification of biosynthesis pathways to control the formation of cysteine and/or glutathione as trapping agents (Horticulture, breeding, genetic modification). 


\section{REFERENCES}

Ahn, J.S. \& Castle, L. 2003. Tests for polymerization of polyacrlamides as a potential source of acrylamide in heated food . J . Agric. Food Chem., 51: 6715-6718.

Amrein, T.M., Bachmann, S., Noti, A., Biedermann, M., Barbosa, M.F., Biedermann-Brem, S., Grob, K., Keiser, A., Realini, P., Escher, F. \& Mado, R. 2003. Potential of acrylamide formation, sugars and free asparagines in potatoes : A composition of cultivars and farming systems. J. Agric. Food Chem. 51: 55565560 .

Anonymous 2002a. Acrylamide in food. JIFSANNCFST Workshop, October 28-30: 2002.

Http://www.jifsan.umd.edu/acryl-amide/wgs risk co mm-final-paper-pdf.htm.

Anonymous 2002b. Overview of Acrylamide Toxicity and Metabolism. JIFSAN NCFST Workshop on Acrylamide in Food. Toxicology and Metabolic Consequences Working Group. October 28-30: 2002.

Barber, D.S., Hunt, J.R., Ehrich, M.F., Lehning, E.J. \& Lopachin, R.M. 2001. Metabolism, toxcokinetics and haemoglobin adduct formation in rats following subacute and subchronic acrylamide dosing. Neurotoxicology, 22: 241-253.

Becalski, A., Lau, B., Lewis, D., \& Seaman, S. 2002. Acrylamide in Foods: Occurance and Sources. Abstracts, $116^{\text {th }}$ Annual AOAC International Meeting, Los Angeles, CA, Sep. 22-26: 2002

Becalski,A., Lau, B., Lewis, D. \& Seaman, S. 2003. Acrylamide in foods: Occurrence, sources and modeling. J. Agric. Food Chem., 51: $802-808$.

Biederman, M., Noti, A., Biederman-Brem, S., Mozzetti, V. \& Grob, K. 2002. Experiments on acrylamide formation and possibilities to decrease the potential of acrylamide formation in potatoes. Mitt. Geb. Lebensmittelunters Hyg. 93: 668-387.

Biederman, M., Biederman-Brem, S., Noti, A., Grob, K., Egli, P. \& Mandli, H. 2003. Two GC-MS methods for the analysis of acrylamide in foodstuffs. Mitteilungen aus Lebensmittel-untersuchung und Hygiene (in print).

Brandl, F., Demiani, S., Ewender, J., Franz, R., Gmeiner, M., Gruber,L., Gruner,A., Schlummer, M., Smolic, S., Stormer, A. \& Wolz, G. 2002. A rapid and convenient procedure for the determination of acrylamide in foodstuff. Electronic Journal of Environmental, Agricultural and Food Chemistry, 1 (3). ISSN: 1579-4377.

Bull, R.J., Robinson, M., Laurie, R.D., Stoner, G.D., Greisiger, E., Meier, J.R., \& Stober, J. 1984. Carcinogenic effects of acrylamide in Sencar and A/J mice. Cancer Res., 44: 107111.

Calleman, C.J., Bergmark, E. \& Costa, L.G. 1990. Acrylamide is metabolized to glycidamide in the rat: Evidence from haemoglobin adduct formation. Chem. Res. Toxicol., 3: 406-412.

Carlson, G.P., Fossa, A.A., Morse, M.A. \& Weaver, P.M. 1986. Binding and distribution studies in the Sencar mouse of compounds demonstrating route-dependent tumorigenic effect. Environ Health Prespect, 68: 53-60.

Castle, L., Campose, M.J. \& Gilbert, J. 1991. Determination of acrylamide monomer in hy- droponically grown tomato fruits by capillary GC-MS. J. Sci. Food Agric. 54: 549-555.

Chapin, R.E., Fail, P.A., George, J.D., Grizzle, T.B., Heindel, J.J., Harry, G.J., Collins, B.J., $\&$ Teague, J. 1995. The reproductive and neural toxicities of acrylamide and three analogues in Swiss mice, evaluated using the continuous breeding protocol. Fundam. Appl. Toxicol, 27: 9-24.

Coffin, R.H., Yada, R.Y., Parkin, K.L., Gradzinski, B. \& Stanley, D.W. 1987. Effect of lowtemperature storage on sugar concentrations and chip colour of certain processing potato cultivars and selections. J. Food Sci. 52: 639645.

Cupta, R.P. \& Abou-Donia, M.B. 1996. Alerations in the neutral proteinase activities of central and peripherol nervous systems of acrylamide, carbon disulfide-, or 2,5hexanedione-treated rats. Mol. Chem. Neuropathol, 29: 53-66.

Dearfield, K.L., Douglas, G.R., Ehling, U.h., Moore, M.M., Sega, G.A. \& Brusick, D.J. 1995. Acrylamide: A review of its genotoxicity and an assessement of heritable genetic risk. Muta. Res., 330: 71-99.

Eppendorfer, W.H. \& Bille, S.W. 1996. Free and total amino acid composition of edible parts of beans, kale, spinach, caudiflower and potatoes as influenced by nitrogen fertilization and phosphorus and postassium deficiency. J. Sci. Food Agric., 71: 440-458.

FAO/WHO 2002. Health implication of acrylamide in food. The final report of a joint FAO/WHO consulation, Geneva, Switzerland, June 25-27.

Fennell, T.R., Synder, R.W, Krol, W.L. \& Sumner, S.C. 2003. Comparison of the heamoglobin adducts formed by administration of $\mathrm{N}$ methylolacrylamide to rats. Toxicol. Sci., 71: 164-175.

Friedman, M. 1973. The Chemistry and Biochemistry of the Sulfhydryl Group in Amino Acids, Peptides and Proteins Permagon Press, Oxford, U.K., pp. 485.

Friedman, M. 2003. Chemistry, biochemistry and safety of acrylamide: A Review. J. Agric. Food Chem., 51: 4504-4526.

Friedman, M. \& Williams, L.A.D. 1977. A mathematical analysis of kinetics of consecutive, competitive reactions of protein amino groups. Adv. Med. Biol., 86B: 299-319.

Friedman, M.A., Duak, L.H. \& Stedham, M.A. 1995. A lifetime oncogenicity study in rats with acrylamide. Fundam. Appl. Toxicol, 27: 95-105.

Godin, A.C., Bengtsson, B., Niskanen, R., Tareke, E., Tornqvist, M. \& Forslund, K. 2002. Acrylamide and N-methylolacrylamide poisoning in a herd of charolais crossbreed cattle. Vet. Res., 1151: 724728.

Granath, F., Ehrenberg, L., Paulsson, B. \& Tornqvist, M. 2001. Cancer risk from exposure to occupational acrylamide. Occup. Environ. Med., 58: 608-609.

Hagmar, L, Tornqvist, M., Nordander, C., Rosen, I., Bruze, M., Kautiainen, A., Magnusson, A.L., Malmberg, B., Apera, P., Granath, F. \& Axmon, A. 2001. Health effects of occupational exposure to acrylamide using haemoglobin adducts as biomarkers of internal dose, Scand. J. Work Environ. Health, 27: 219-226. 
Hashimoto, K. \& Tanii, H. 1985. Mutagenicity of acrylamide and its analogues in Salmonella typhimurium. Mutat. Res., 158: 129-133.

He, F.Z., Zhang, S.L., Wang, H.L., Li, G., Zhang, Z.M., li, F.L., Dong, X.M. \& Hu, F. 1989. Neurological and electroneuro-myographic assessment of the adverse effects of acrylamide on occupationally exposed workers. Scand. J. Work Environ. Health, 15: 125-129.

Hofler, F., Maurer, R. \& Cavalli, S. 2002. Rapid analysis of acrylamide in foods with ASE and LC/MS. GIT Labor-Fachzect, 46: 968-970.

IARC 1994. IARC monographs on the evaluation of carcinogenic risks to humans. International Agency for Research on Cancer. 60: 389-433. IARC-Lyon, France.

Khanna, V.K., Husain, R. \& Seth, P.K. 1988. Low protein diet modifies acrylamide neurotoxicity. Toxicology, 49: 395-401.

Khanna, V.K., Husain, R. \& Seth, P.K. 1992. Protein mal nourishment: A predisposing factor in acrylamide toxicity in pregnant rats. $J$. Toxicol. Environ. Health, 36: 293-305.

Kirman, C., Gargas, M., Deskin, R., TonnerNavarro, L. \& Andersen, M. 2003. A physiologically based pharmacokinetic model for acrylamide and its metabolite, glycidamide, in the rat. J. Toxicol. Environ. Health, Part A, 66: 253-274.

Lindsay, R. 2002. Generalized potential origins of acrylamide in foods. Workshop on Food Research Institute (FRI) Acrylamide Project. Chicago, O’Hare Hilton-June 4: 2002.

LoPochin, R.M 2002. The role of fast axonal transport in acrylamide pathosphysiology: Mechanism or epiphenomenona. Neurotoxicology, 23: 223-251.

LoPochin, R.M., Ross, J.F. \& Lehning, E.J. 2002a. Nerve terminals as the primary site of acrylamide action. A hypothesis. Neurotoxicology, 23: 43-59.

LoPochin, R.M., Ross, J.F., Reid, M.1.. Das, S., Mansukhani, S., \& Lehning, E.J. 2002b. Neurological evaluation of toxic axonopathies in rats: Acrylamide and 2,5 hexanedione. Neurotoxicology, 23: 95-110.

Martenson, C.H., Odom, A., Sheetz, M.P. \& Graham, D.G. 1995. The effect of acrylamide and other sulfhydryl alkylators on the ability of dynein and kinesin to translocate microtubules in vitro. Toxicol. Appl. Pharmacol, 133: 73-81.

Miller, M.J., Carter, D.E. \& Sipes, I.G. 1982. Pharmacokinetics of acrylamide in Fisher334 rats. Toxicol. Appl. Pharmacol. 63: 3644.

Miller, M.S. \& Spencer, P.S. 1985. The mechanism of acrylamide axonopathy. Annu, Rev. Pharmacol. Toxicol., 25: 643-660.

Mottram, D.S. \& Wedzicha, B. 2002. Suggested mechanisms for the formation of acrylamide in foods: Workshop on Food Research Institute (FRI) Acrylamide Project. Chicago, O'Hare Hilton, June 4: 2002.

Mottram, D.S., Wedzicha, B.L., Dodson, A.T. 2002. Acrylamide is formed in Maillard reaction . Nature, 419: 448-449.

Naewbanij, J.O. 2002. Acrylamide in food: A serious but not a public health emergency issue. A report of the Swedish National Food Institute (NFA). Department of Information Services.
NTP 1998. Toxicology and Carcinogenesis Studies of N-Methylol-acrylamide (CAS No. 92442-5) in F 344/N Rats and B6C3 1 Mice (Gavage Studies). Natl. Toxicol. Program Tech. Rep. Ser., 352: 1-204.

Odland, I., Romert, L., Clemedson, C. \& Walum, E. 1994. Glutathione content, glutathione transferase activity and lipid peroxidation in acrylamide-treated neuroblastoma NIE 115 cells. In vitro Toxicol, 8: 263-267.

Paulsson, B., Kotova, N., Grawe, J., Henderson, A., Granath, F., Golding, B. \& Tornqvist, M. 2003. Induction of micromucleir in mouse and rat by glycidiamide, gentoxic metabolite by acrylamide. Mutant. Res., 58: 608-609.

Riha, W.E., Izzo, H.V., Zhang, J. \& HO, C.T. 1996. Non-enzymatic deamination of food proteins. Critical Reviews in Food Science and Nutrition, 36: 225-255.

Roe, M.A., Faulks, R.M. \& Belsten, J.L. 1990. Role of reducing sugars and amino acids in fry colour of chips from potatoes grown under different nitrogen regimes. J. Sci. Food Agric., 52: 207-214.

Rosen, J.D. 2002. Acrylamide in food. Is it a real threat to public health? A position paper of the American Council on Science and Health. http:

//Www.acsh.org/publication/reports/acrylamid e2002.pdf.htm.

Sakamoto, J. \& Hashimoto, K. 1986. Reproductive toxicity of acrylamide and related compounds in mice, effect on fertility and sperm morphology. Arch. Toxicol., 59: 201-205.

Sanders, R.A., Zyzak, D.V., Stojanovic, M. Tallmadge, D.H., Eberhart, B.L., Ewald, D.K. 2002. An LC/MS acrylamide method and its use in investigating the role of asparagine. Acrylamide Symposium, $116^{\text {th }}$ Annual AOAC International Meeting, Los Angeles, CA, Sep. 26: 2002.

Shelby, M.D., Cain, k.T., Cornett, C.V. \& Generoso, W.M 1987. Acrylamide, induction of heritable translocations in male mice Environ. Mutagen, 9: 363-368.

Smith, O. 1977. Chemical composition of the potato. In potatoes : Production, Storingl Processing, ed 2., Smith, O. Ed. The AVI Publishing Company, Westport, CT. pp. 77-144.

Srivistava, S.P., Sabri, M.I., Agrawal, A.K. \& Seth, P.K. 1986. Effect of single and repeated doses of acrylamide and bis-acrylamide on glutathione-S-transferase and dopamine receptors in rat brain. Brain Res., 37: 319-323.

Stalder, R.H., Blank, I., Varga, N., Robert, F., Hau, J., Guy, P.A., Robert, M.C. \& Riediker, S. 2002. Acrylamide from Maillard reaction products. Nature, 419: 449-450.

Sumner, S.C., Fennell, T.R., Moore, T.A., Chanas, B., Gonzalez, F. \& Chanayem, B. 1999. Role of cytochrome P450 2E1 in the metabolism of acrylamide and acrylonitrile in mice. Chem. Res. Toxicol., 12: 1110-1116.

Sumner, S.C., Selvaraj, L., Nauhaus, S.K. \& Fennell, T.R. 1997. Urinary metabolities from F344 rats and B6C3F1 mice coadministered acrylamide and acrylonitrile for 1 or 5 days. Chem. Res. Toxicol., 10: 1152-1160.

Tareke, E., Rydberg, P., Karlsson, P., Eriksson, S. \& Toemqvist, M. 2000. Acrylamide, a cooking carcinogen. Chem. Res. Toxicol., 13: 517-522. 
Tareke, E., Rydberg, P., Karlsson, P., Eriksson, S. $\&$ Tornquvist, M. 2002. Analysis of acrylamide, carcinogen formed in heated food stuff. J. Agric. Food Chem. Soc.: 4998-5006.

Tyl, R.W. \& Friedman, M.A. 2003. Effects of acrylamide on rodent reproductive performance. Report. Toxicol, 17: 11-13.

Tyl, R.W., Marr, M.C., Myers, C.B. \& Friedman, M.A. 2000. Relationship between acrylamide reproductive and neurotoxicity in male rats. Report. Toxicol., 14: 147-157.

Whitfield, F.B. 1992. Volatiles from interactions of Maillard reactions and lipids. Crit. Rev. Food Sci. Nutri 31: 1-58.

WHO 1996. Guidelines for Drinking-Water Quality, $2^{\text {nd }}$ ed, World Health Organoization, Geneva, S Wise, L.D., Gordon, L.R., Soper, K.A., Duchai, D.M. \& Morissez, K.E. witzerland, 2: 940-949.
Wise,L.D Gordon, L.R, Soper, K.A, Duchai, D.M. \& Morissez, K.E. 1995. Developmenal neurotoxicity evaluation of acrylamide Spargue-Dawley rats. Neurotoxicol. Teratol., 17: 189-198.

Wu, Y.Q., Yu, A.R., Tang, X.y., Zhang, J. \& Cui, T. 1993. Determination of acrylamide metabolite, mercapturic acid by high performance liquid chromatography. Biomed. Environ. Sci., 6: 273-280.

Yasuhara, A., Tanaka, Y., Hengel, M. \& Shibamoto, T. 2003. Gas chromatographic investigation of acrylamide formation in browning model system. J. Agric. Food Chem., 51: 3999-4003.

Zenick, H, Hope, E. \& Smith, M.K. 1986. Reproductive toxicity associated with acrylamide treatment in male and female mice. J. Toxicol. Environ, Health, 17: 457-472. 


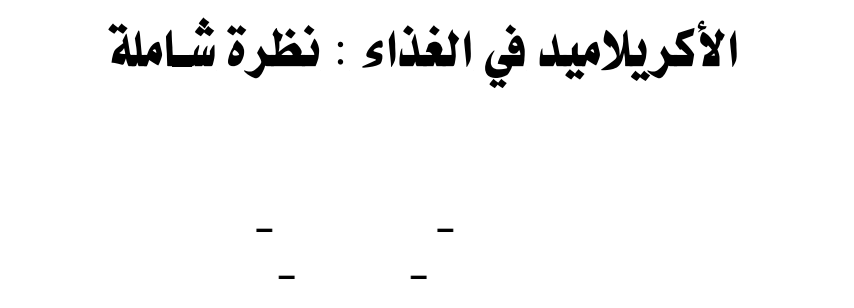

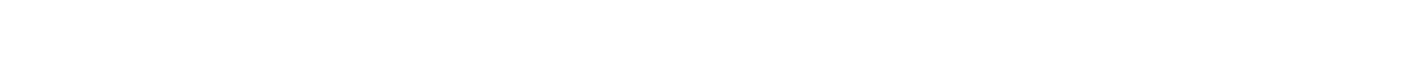

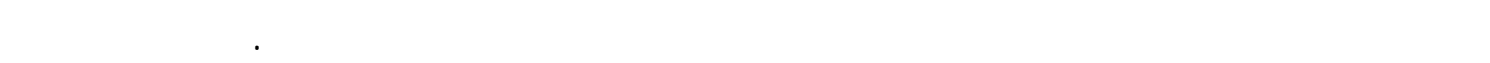

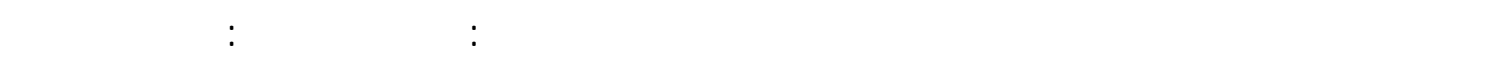

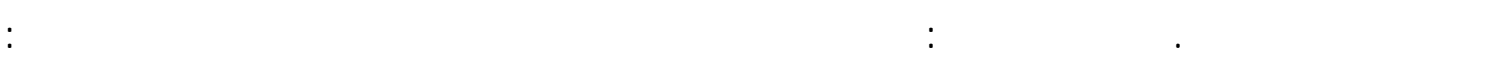

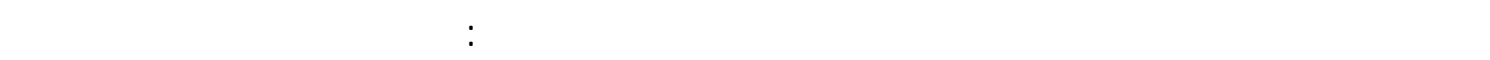

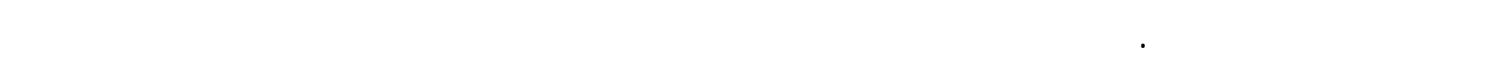

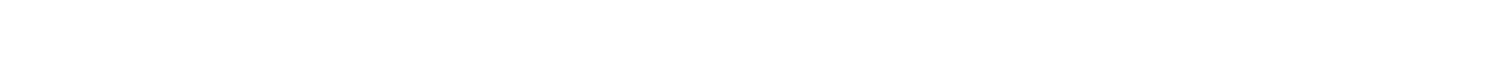

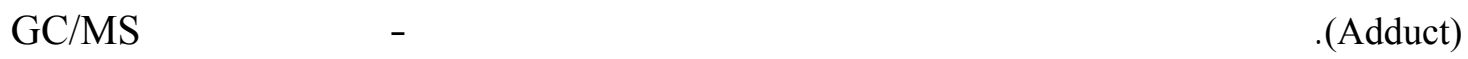

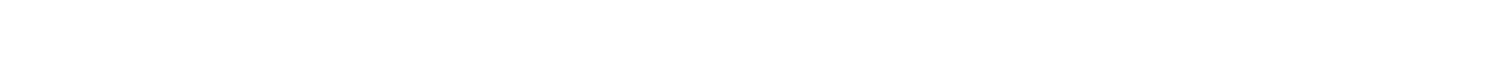

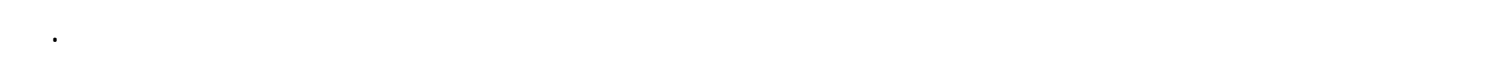

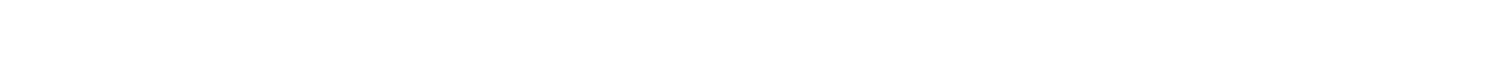

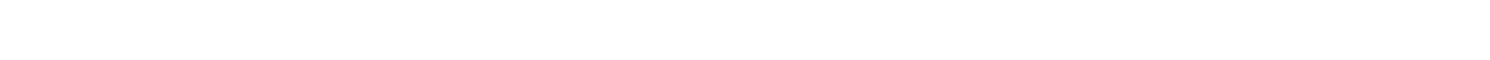

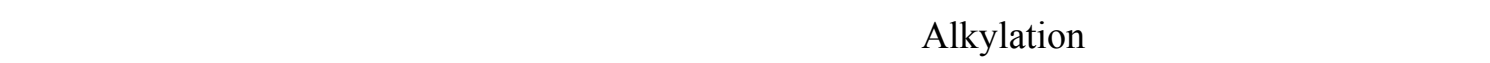

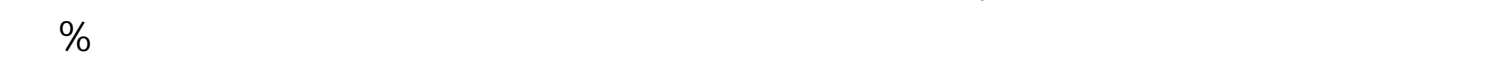

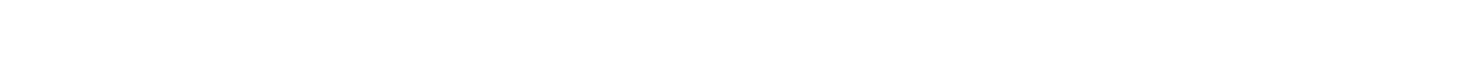

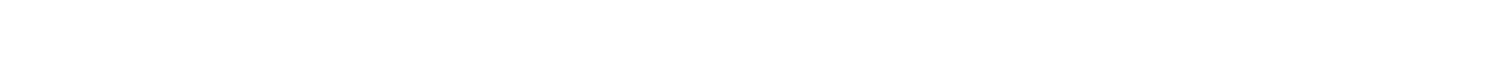

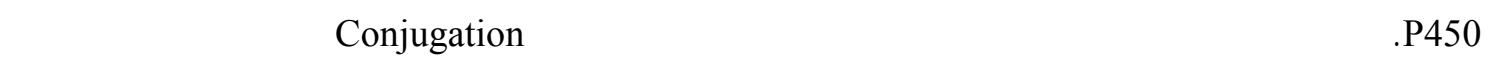
من خلا GSH

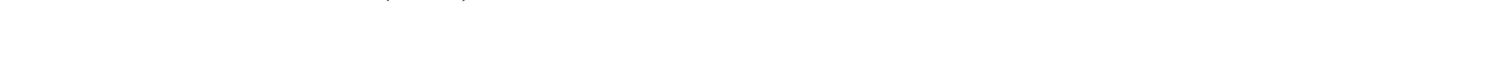

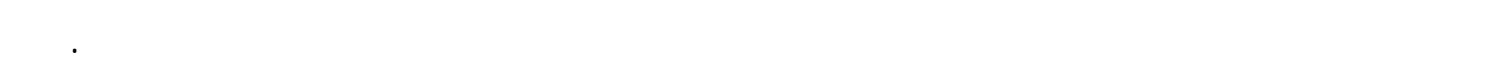

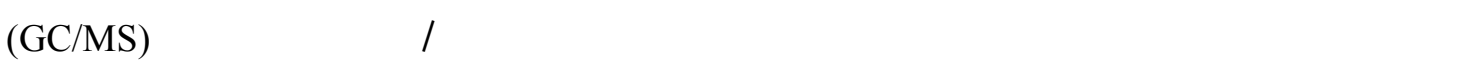

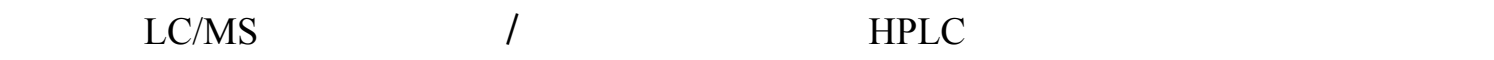

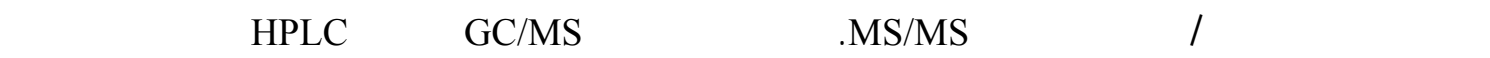

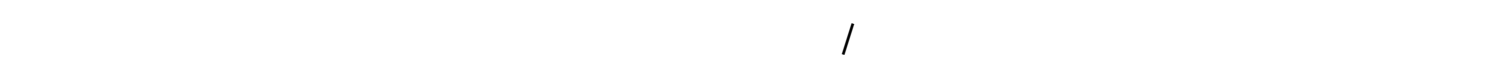

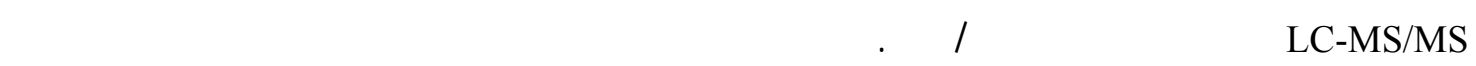
في عمليك التحليل الروتيفي. 